Ann. Biol. anim. Bioch. Biophys., I963, 3 (3), 263-2,98

\title{
ÉTUDE DE L'AJUSTEMENT DE LA CONSOMMATION SPONTANÉE D'ÉNERGIE EN FONGTION DE L'APPORT AZOTÉ CHEZ LE RAT EN GROISSANCE
}

\author{
A. RÉRAT et Y. HENRY \\ avec la collaboration technique de G. Rouzer, Yvonne DanieL, \\ Françoise Houlier et Marie-Claire Theron \\ Station de Recherches sur l'Elevage des Porcs, \\ Centre national de Recherches zootechniques, Jouy-en-Josas (Seine-et-Oise)
}

SOMMAIRE

La consommation spontanée d'énergie chez le Rat en croissance a été étudiée en distribuant, dans deux mangeoires séparées, un régime protéique en quantité fixe et un régime protéiprive offert ad libitum. Trois sources azotées d'origine connue (farine de poisson de Norvège, tourteau d'arachide d'extraction, gluten de blé) ont été utilisées, chacune à 3 niveaux $(0,6, \mathrm{I}, 2$ et $\mathrm{I}, 8 \mathrm{~g}$ de protéines par jour), au cours d'une série d'expériences portant sur des lots de 8 à i 2 rats blancs de souche Wistar.

Jorsque le besoin azoté pour une croissance maximum n'est pas couvert, la consommation spontanée d'énergie augmente avec le niveau azoté ; à un niveau azoté donné, elle est d'autant plus élevée que la source azotée est de meilleure qualité. Le rapport énergie/azote diminue lorsque la quantité d'azote administrée augmente ou lorsqu'on utilise une source azotée de valeur biologique moindre. Dans tous les cas, l'accroissement de la consommation d'énergie entraîne une amélioration de la croissance, de l'indice de consommation, des rétentions azotée et énergétique

Quels que soient le niveau azoté et la nature de la source azotée, l'ingestion de calories est proportionnelle au poids élevé à une puissance fixe (voisine de 0,5 dans l'intervalle de poids $60-150 \mathrm{~g}$ ); elle est également proportionnelle à la quantité d'azote retenue dans les tissus. Enfin, à un poids donné, la composition corporelle est la même quelle que soit la nature de la source azotée. Ces observations confirment l'existence d'un phénomène d'ajustement de la consommation d'énergie en fonction de l'impulsion de croissance permise par les protéines qui constituent dans le cas présent le facteur limitant.

\section{INTRODUCTION}

L'étude de la consommation spontanée d'éléments azotés et énergétiques par la méthode du libre choix, chez le Rat en croissance, a permis de montrer que ce dernier est incapable d'ajuster son ingestion azotée au niveau de son besoin ; par contre, sa consommation d'énergie est en relation constante avec le poids aux diffé- 
rents stades de la croissance, quelle que soit la nature de la source azotée (HENRY et RERAT, I963). De leur côté, CALET et al. (I96I) ont observé que, lorsque le poulet reçoit, en deux repas séparés, une quantité limitée d'une protéine de nature variable et des éléments énergétiques ad libitum, il ingère une quantité d'énergie variable selon la nature de la source azotée.

Compte tenu de ces observations, nous avons réalisé une série d'expériences sur le Rat dans le but d'étudier l'évolution de la consommation spontanée d'énergie, selon que l'on fait varier la quantité de protéines administrées et la nature de ces dernières.

\section{MATÉRIEL, E'T MÉTHODES}

Une série d'expériences, portant sur l'administration séparée et simultanée d'éléments azotés en quantité limitée et d'éléments énergétiques à volonté, a été réalisée sur des rats de souche Wistar $C F$, mâles et femelles, pris au sevrage et élevés en cages individuelles Selon les expériences, il s'agit dé faire varier le niveau de l'apport azoté et/ou la nature de la source azotée. A cet effet, trois sources azotées de qualité différente sont utilisées : une farine de hareng de Norvège, un tourteau d'arachide d'extraction et un gluten de blé, dont les caractéristiques ont été précisées dans une publication antérieure, de même que la composition du régime préexpérimental à base de caséine auquel sont soumis les animaux avant le début de l'expérience (HENRY et RERAT, I963). Deux expériences préliminaires ont d'abord été tentées pour déterminer les conditions de l'expérimentation ; une série de 5 expériences a été ensuite réalisée.

\section{Expériences prélimunaires}

\section{I. - Expérience $P_{1}$.}

Une première expérience préliminaire a pour objet de préciser les conditions d'application de la méthode d'administration séparée des repas azoté et non azoté. Il s'agit en particulier de fixer la quantité de matières azotées à distribuer chaque jour, quantité qui doit être inférieure à celle qui assure la croissance maximum. En effet, l'étude de la relation entre la consommation d'énergie et l'apport azoté implique que l'azote soit utilisé comme source de matière azotée pour la croissance et l'entretien, ce qui n'est plus le cas dès que l'on se place au-dessus du niveau correspondant à la croissance maximum.

3 o rats mâles reçoivent pendant 3 jours un régime préexpérimental à base de caséine. Pendant les 3 jours suivants on leur distribue simultanément, dans deux mangeoires séparées, d'un côté de la farine de poisson à l'état pur $(\mathrm{P})$, de l'autre un régime protéiprive (E) à base de sucre, huile, cellulose, minéraux et vitamines, dont la composition a été rapportée dans une publication précédente (HENRY et RERAT, 1962). On laisse la consommation spontanée s'établir d'une manière progressive et à l'issue de cette période on constate que les animaux ingèrent librement en moyenne $5, \mathrm{I} g$ de protéines et $18,2 \mathrm{~g}$ de matière sèche par jour, soit $28 \mathrm{p}$. Ioo de protéines par rapport à la matière sèche.

3 lots homogènes de Io animaux sont alors constitués et reçoivent quotidiennement pendant 34 jours, en deux repas séparés : une quantité fixe de protéines de poisson, sensiblement inférieure à celle enregistrée au cours de la période préexpérimentale, soit 4,3 et $2 \mathrm{~g}$ selon les lots, - le régime protéiprive $\mathrm{E}$ à volonté.

De même que dans les expériences qui suivent, les consommations individuelles de nourriture sont enregistrées quotidiennement et les animaux sont pesés deux fois par semaine. La consommation spontanée d'énergie est exprimée en calories totales, d'après les coefficients d'ATwATER et BRYANT (I903). Les animaux sont sacrifiés à la fin de l'expérience et leurs carcasses sont analysées suivant une technique qui a déjà été exposée, de même que les modalités du calcul de la rétention azotée et de la rétention énergétique d'après les résultats de la composition corporelle au début et à la fin de l'expérience (Henry et Rerat, I963).

$$
\text { 11. - Expérience } P_{2} \text {. }
$$

Une deuxième expérience préliminaire a pour but de déterminer dans quelle mesure l'utilisation des matières azotées est modifiée selon que la source azotée est apportée complètement séparée du régime protéique ou en combinaison avec une fraction de ce dernier. Il a été constaté en effet que 
le rat, qui s'habitue très vite à ce mode d'alimentation, ingère la totalité du repas azoté et une partie seulement du repas non azoté sitôt leur distribution, le complément de l'énergie étant consommé au cours de la nuit; il en résulte un décalage possible dans le temps entre l'ingestion des éléments azotés et celle des éléments énergétiques. Dans ces conditions, et à la suite des observations de GEIGER (I948), on peut se demander si l'administration simultanée de l'azote et d'une fraction de l'énergie n'entraîne pas une meilleure utilisation de l'azote, par suite d'une action d'épargne de l'énergie sur l'azote. Deux lots de $\mathrm{I} 2$ rats ( 7 mâles et 5 femelles) sont ainsi comparés, recevant $\mathrm{I}, 2 \mathrm{~g}$ de protéines de poisson par jour :

- soit à l'état pur (lot P),

- soit sous forme d'un régime constitué par parties égales de la farine de poisson et du régine précédent (lot PE).

Dans les deux cas, le régime protéiprive est administré à volonté. La durée de l'expérience est de 8 semaines.

\section{Expériences $\mathrm{I} \dot{a} \mathrm{~V}$}

Cinq expériences successives sont réalisées, basées sur le même principe de l'administration séparée d'un repas protéique en quantité limitée et d'un repas protéiprive ad libitum. Le régime protidique est constitué d'une des 3 sources azotées considérées : farine de poisson de Norvège, tourteau d'arachide, gluten de blé, et est donné en quantité fixe à chaque animal, mais à 3 niveaux pour chacune des 3 sources azotées envisagées (respectivement $0,6-1,2$ et $\mathrm{I}, 8 \mathrm{~g}$ de matières azotées par jour, soit 96 , I92 et $288 \mathrm{mg}$ d'azote). Ces quantités ont été choisies d'après les résultats de la première expérience préliminaire, celles primitivement fixées $(2,3$ et $4 \mathrm{~g})$ s'étant avérées excessives.

Le schéma des 5 expériences est donné ci-après :

\begin{tabular}{|c|c|c|c|c|c|}
\hline \multirow{2}{*}{ Expérience No } & \multirow{2}{*}{ Source azotée } & \multirow{2}{*}{$\begin{array}{l}\text { Quantité de protéines } \\
\qquad(\mathrm{N} \times 6,25), \mathrm{g} / \mathrm{j}\end{array}$} & \multicolumn{2}{|c|}{ Nombre d'animaux par lot } & \multirow{2}{*}{$\begin{array}{c}\text { Durée } \\
\text { (en jours) }\end{array}$} \\
\hline & & & Mâles & Femelles & \\
\hline I & Poisson . . . . . . . & $1,8-1,2-0,6$ & 8 & & 140 \\
\hline II & $\begin{array}{l}\text { Poisson } \ldots \ldots \ldots \\
\text { Arachide } \ldots \ldots\end{array}$ & $\begin{array}{c}1,2 \\
1,8-1,2-0,6\end{array}$ & 10 & & 125 \\
\hline III & $\begin{array}{l}\text { Poisson } \ldots \ldots \ldots \ldots \\
\text { Gluten } \ldots \ldots \ldots \ldots\end{array}$ & $\begin{array}{c}1,2 \\
1,8 \cdot 1,2-0,6\end{array}$ & 5 & 4 & 57 \\
\hline IV & $\begin{array}{l}\text { Poisson } \ldots \ldots \ldots \\
\text { Arachide } \ldots \ldots \ldots \\
\text { Gluten } \ldots \ldots \ldots \ldots\end{array}$ & $\begin{array}{l}1,2 \\
1,2 \\
1,2\end{array}$ & 7 & 5 & 57 \\
\hline $\mathrm{V}$ & $\begin{array}{l}\text { Poisson } \ldots \ldots \ldots \\
\text { Arachide } \ldots \ldots \ldots\end{array}$ & $\begin{array}{l}1,8-1,2-0,6 \\
1,8-1,2-0,6\end{array}$ & 8 & & 56 \\
\hline
\end{tabular}

A la suite de la deuxième expérience préliminaire, chacune des sources azotées est administrée conjointement avec une fraction du régime protéiprive, de telle façon que le taux de protéines soit compris entre 35 et $4 \circ \mathrm{p}$. 100 pour les trois sources azotées. La composition des régimes a été indiquée dans une note préliminaire (HENRY et RERAT, I962).

Un lot témoin recevant $\mathrm{I}, 2 \mathrm{~g}$ de protéines de poisson par jour est reconstitué d'une expérience à l'autre afin de s'assurer de la reproductibilité des résultats et de comparer ainsi les expériences entre elles.

Les deux premières expériences ont duré respectivement I 40 et I 25 jours, afin d'étudier l'évolution de la consommation d'énergie en fonction de l'âge de l'animal. La durée des expériences suivantes a été de 8 semaines.

Les calculs statistiques ont été effectués suivant la méthode d'analyse de variance et pour la comparaison des moyennes, dans l'expérience IV, le test de KEuls-NEWMAN (SNEDECOR, I956) a été vtilisé. 


\section{RÉSULTATS \\ EXPÉRIENCE PRÉLIMINAIRE $\mathrm{P}_{1}$}

Les résultats généraux de la première expérience préliminaire $P_{1}$ sont rapportés dans le tableau I. Le gain moyen journalier, la consommation d'énergie et la réten-

TABIEAU I

Expérience préliminaire $P_{1}:$ farine de poisson à 3 niveaux - Résultats généraux après 34 jours

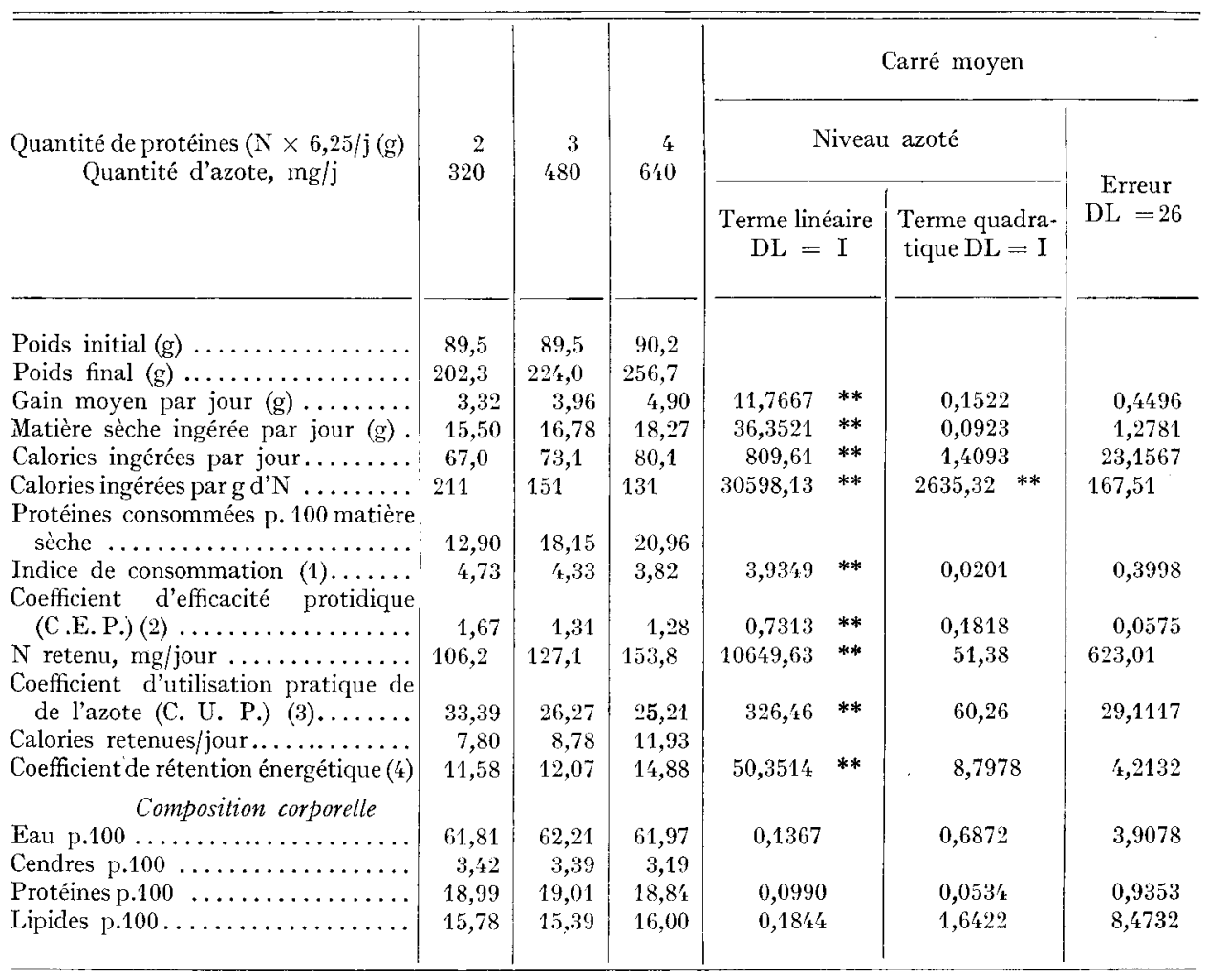

(1) Indice de consommation: $\frac{\text { matière sèche ingérée }(g)}{\text { gain de poids }(g)}$

(2) Coefficient d'efficacité protidique : $\frac{\text { Gain de poids }(\mathrm{g})}{\text { Protéines }(\mathrm{N} \times 6,25) \text { ingérées }(\mathrm{g})}$

(3) Coefficient d'utilisation pratique de l'azote: $\frac{N \text { corporel final }(\mathrm{g})-\mathrm{N} \text { corporel initial }(\mathrm{g})}{\mathrm{N} \text { ingéré }(\mathrm{g})} \times 100$

('́) Coefficient de rétention énergétique : $\frac{\text { calories finales - calories initiales }}{\text { calories ingérées }} \times 100$

Équations de régression, en fonction de la quantité d'azote $(\mathrm{N})$ administré/j :

Gain moyen $/ \mathrm{j}(\mathrm{g})=1,33+0,79(\mathrm{~N} \times 6,25)(\mathrm{g} / \mathrm{j})$

Calories ingérées $/ \mathrm{j}=55,7+40,8 \mathrm{~N}(\mathrm{~g} / \mathrm{j})$

* Seuil de signification 0,05

$\mathrm{N}$ retenu, $\mathrm{mg} / \mathrm{j}=6{ }^{\prime, 7}+0,15 \mathrm{~N}(\mathrm{mg} / \mathrm{j})$

** Seuil de signification 0,01 . 
tion azotée augmentent linéairement avec la quantité d'azote administrée. Si l'on rapporte ces données à l'apport azoté, on obtient des valeurs correspondant au coefficient d'efficacité protidique (C. E. P.), à la quantité de calories par g d'azote, et au coefficient d'utilisation pratique de 1'azote (C. U. P.) : d'après les équations de régression correspondantes, la valeur de ces critères relativement à 1'apport azoté diminute lorsque celui-ci s'élève. Par contre, la rétention énergétique augmente avec le niveau azoté, tant en valeur relative par rapport à l'ingestion d'énergie qu'en valeur absolue. Ces phénomènes opposés sont dus au fait que la consommation d'énergie croît moins vite que la consommation de protéines; il en résulte que le pourcentage de protéines dans la ration sèche passe de $\mathrm{I}_{3}$ à $2 \mathrm{I}$ p. Ioo lorsqu'on double la quantité d'azote. De même que la rétention énergétique, l'indice de consommation est amélioré lorsque les rats reçoivent davantage d'azote.

L'examen des résultats de composition corporelle fait ressortir une grande similitude d'un lot à l'autre, malgré des variations relativement importantes dans le poids des animaux en fin d'expérience.

\section{EXPÉRIENCE PRÉLIMINAIRE P 2}

Les résultats de la deuxième expérience préliminaire sont donnés dans le tableau 2. Quel que soit le critère envisagé, il n'existe pas de différence significative entre les deux lots $P$ et PE, et ceci pour les animaux des deux sexes. Cependant les différences, si elles ne sont pas significatives, vont toutes dans le même sens et il semble que l'administration de la farine de poisson en mélange avec une fraction des éléments énergétiques ait tendance à provoquer une amélioration de la croissance et de la rétention azotée, alors que la consommation d'énergie est la même. Il est possible qu'il existe une certaine action d'épargne de l'azote par l'énergie.

Il est à noter une influence marquée du sexe sur les résultats de croissance et de consommation; les mâles se révêlent à tous points de vue supérieurs aux femelles. Par contre, la composition corporelle est la même dans les deux cas.

\section{EXPÉRIENCES I à V}

\section{A. - Résultats généraux de croissance et de consommation}

$\left.\mathrm{I}^{\circ}\right)$ Résultats après I40 jours (expérience I) et I25 jours (expérience II) :

Les expériences I et II ont été réalisées sur des périodes relativement longues, respectivement $\mathrm{I} 4 \mathrm{O}$ et $\mathrm{I} 25$ jours; les résultats correspondants sont rassemblés dans le tableau 3. On remarque que pour le poisson, comme pour 1'arachide, la vitesse de croissance augmente linéairement avec la quantité de protéines, lorsque cette dernière passe de $0,6 \mathrm{~g}$ à $\mathrm{I}, 8 \mathrm{~g}$ par jour, alors que la quantité de calories ingérées spontanément atteint une limite supérieure entre I, 2 et I, $8 \mathrm{~g}$ de protéines. En valeur relative, leno mbre de calories ingérées parg d'azote diminue lorsque le niveau azoté s'élève.

En ce qui concerne le C. E. P. et le C. U. P., l'évolution est différente pour les deux sources azotées. Dans le cas du poisson, on obtient une décroissance linéaire de ces deux coefficients entre 0,6 et $\mathrm{I}, 8 \mathrm{~g}$ de protéines par jour ; dans le cas de 1'arachide, les mêmes coefficients augmentent jusqu'à un maximum entre $I, 2$ et $\mathrm{I}, 8 \mathrm{~g}$ de protéines par jour. 


\section{TABLEAU 2}

Expérience préliminaire $P_{2}$ : infuence du mode d'administration de la fraction azotée : à l'etat pur ou en mélange avec une fraction des éléments énergétiques - Résultats généraux après 57 jours

\begin{tabular}{|c|c|c|c|c|}
\hline $\begin{array}{l}\text { Nature de la protéine } \\
\text { Quantité de protéines/j (g) }\end{array}$ & \multicolumn{4}{|c|}{$\begin{array}{l}\text { Farine de poisson } \\
\qquad 1,2\end{array}$} \\
\hline Sexe & \multicolumn{2}{|c|}{ Mâles } & \multicolumn{2}{|c|}{ Femelles } \\
\hline Lot & $\mathrm{P}$ & $\mathrm{PE}$ & $\mathrm{P}$ & $\mathrm{PE}$ \\
\hline Poids initial $(g) \ldots \ldots \ldots \ldots \ldots \ldots$ & 76,8 & 75,4 & 73,0 & 73,2 \\
\hline Poids final (g) $\ldots$. & 205,6 & 209,8 & 169,2 & 176,4 \\
\hline Gain moyen $/ \mathrm{j}(\mathrm{g}) \ldots \ldots \ldots$ & 2,26 & 2,36 & 1,69 & 1,81 \\
\hline Matière sèche ingérée/j (g) . & 12,35 & 12,40 & 11,17 & 11,54 \\
\hline Calories ingérées $/ j \ldots \ldots \ldots$. & 53,7 & 53,9 & 48,7 & 50,3 \\
\hline Calories ingérées par $\mathrm{g} d \mathrm{~d}^{\mathrm{N}} \mathrm{N} \ldots \ldots \ldots \ldots \ldots \ldots \ldots$ & 281 & 285 & 256 & 265 \\
\hline Protéines consommées p. 100 matière sèche.......... & 9,68 & 10,03 & 10,71 & 10,31 \\
\hline Indice de consommation $\ldots \ldots \ldots \ldots \ldots \ldots \ldots$ & 5,49 & 5,27 & 6,68 & 6,37 \\
\hline 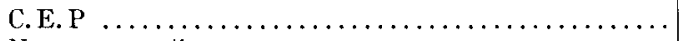 & 1,89 & 1,98 & 1,42 & 1,52 \\
\hline $\mathrm{N}$ retenu, $\mathrm{mg} / \mathrm{j} \ldots \ldots \ldots \ldots \ldots \ldots \ldots \ldots \ldots \ldots$ & 71,6 & 75,6 & 55,8 & 59,1 \\
\hline C. U.P., & 37,52 & 39,82 & 29,25 & 31,17 \\
\hline Calories retenues $/ \mathrm{j} \ldots \ldots \ldots \ldots \ldots \ldots \ldots \ldots$ & 5,95 & 6,27 & 5,07 & 5,10 \\
\hline Coefficient de rétention énergétique $\ldots \ldots \ldots \ldots \ldots \ldots$ & 11,10 & 11,72 & 10,52 & 10,12 \\
\hline \multicolumn{5}{|l|}{ Composition corporelle } \\
\hline Ea u $.100 \ldots \ldots$ & 64,43 & 63,98 & 62,24 & 63,21 \\
\hline Cendres p.100 $\ldots \ldots \ldots \ldots \ldots \ldots \ldots \ldots \ldots$ & 3,46 & 3,54 & 3,97 & 4,05 \\
\hline 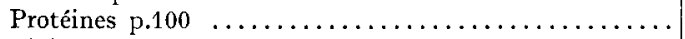 & 18,82 & 19,02 & 19,15 & 19,11 \\
\hline 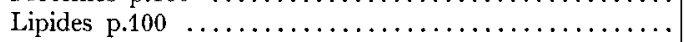 & 13,29 & 13,46 & 14,64 & 13,63 \\
\hline
\end{tabular}

Analyse de variance

\begin{tabular}{|c|c|c|c|c|}
\hline \multirow[b]{2}{*}{ Critère } & \multicolumn{4}{|c|}{ Carré moyen } \\
\hline & $\begin{array}{c}\text { Traitement } \\
\text { DI }=1\end{array}$ & $\begin{array}{c}\text { Sexe } \\
\mathrm{DL}=1\end{array}$ & $\begin{array}{c}\text { Interaction } \\
\mathrm{DL}=1\end{array}$ & $\begin{array}{c}\text { Erreur } \\
\mathrm{DI}=19\end{array}$ \\
\hline Gain moyen $/ j \ldots$. & 0,0676 & $1,7678 * *$ & 0,0006 & 0,02674 \\
\hline Calories ingérées $/ j \ldots \ldots \ldots \ldots \ldots \ldots \ldots \ldots$ & 3,5957 & $103,3137 *$ & 2,5252 & $12,6 \div 07$ \\
\hline Indice de consommation $\ldots \ldots \ldots \ldots \ldots \ldots \ldots \ldots$ & 0,3637 & $7,3798 * *$ & 0,0115 & 0,3334 \\
\hline $\mathrm{N}$ retenu, $\mathrm{m}, \mathrm{j}, \ldots \ldots \ldots \ldots \ldots \ldots \ldots \ldots \ldots \ldots \ldots \ldots$ & 70,79 & $1472,16 * *$ & 0,92 & 27,24 \\
\hline Calories retenues $/ j \ldots \ldots \ldots \ldots \ldots \ldots \ldots \ldots \ldots$ & 0,2132 & 5,9613 & 0,1195 & 1,4024 \\
\hline Composition corporelle & & & & \\
\hline Protéines p.100 $\ldots \ldots \ldots \ldots \ldots \ldots \ldots \ldots \ldots \ldots \ldots$ & 0,0447 & 0,2394 & 0,0812 & 0,7124 \\
\hline Lipides ${ }^{1} 100 \ldots \ldots \ldots \ldots \ldots \ldots \ldots \ldots \ldots \ldots$ & 0,6075 & 2,8408 & 2,0978 & 15,1470 \\
\hline
\end{tabular}

* Seuil de signification 0,05 .

** Seuil de signification 0,01 . 
TABLEAU 3

Expériences $I$ et II : farine de poisson et tourteau d'arachide à 3 niveaux - Résultats généraux de croissance et de consommation après r 40 jours (expérience $I$ ) et 125 jours (expérience II)

\begin{tabular}{|c|c|c|c|c|c|c|c|}
\hline \multirow{2}{*}{ Nature de la protéine } & \multicolumn{3}{|c|}{ Expérience I } & \multicolumn{4}{|c|}{ Expérience II } \\
\hline & \multicolumn{3}{|c|}{ Poisson } & \multirow{2}{*}{ Poisson } & \multicolumn{3}{|c|}{ Arachide } \\
\hline Quantité de protéines $(\mathrm{g} / \mathrm{j})$ & 0,6 & 1,2 & 1,8 & & 0,6 & 1,2 & 1,8 \\
\hline Poids initial $(\mathrm{g}) \ldots \ldots \ldots \ldots \ldots \ldots \ldots \ldots \ldots$ & 63,2 & 63,2 & 63,2 & 77,5 & 75,7 & 77,4 & 77,4 \\
\hline Poids final $(g) \ldots \ldots \ldots \ldots \ldots \ldots \ldots \ldots$ & 213,1 & 312,1 & 367,7 & 301,5 & 143,3 & 230,3 & 294,7 \\
\hline Gain moyen $/ \mathrm{j}(\mathrm{g}) \ldots \ldots \ldots \ldots$ & 1,07 & 1,78 & 2,17 & 1,79 & 0,54 & 1,22 & 1,74 \\
\hline Matière sèche ingérée $/ \mathrm{j}(\mathrm{g}) \ldots$. & 11,84 & 14,66 & 14,33 & 12,74 & 8,84 & 11,73 & 13,03 \\
\hline Calories ingérées $/ \mathbf{j} \ldots \ldots \ldots \ldots \ldots \ldots \ldots \ldots$ & 51,2 & 65,5 & 63,0 & 55,6 & 37,7 & 50,2 & 56,0 \\
\hline Calories ingérées par g d'N . . . . . . . . . & 501 & 322 & $214^{\prime}$ & 285 & 370 & 245 & 185 \\
\hline Protéines consommées p. 100 matière sèche... & 5,11 & 8,70 & 12,93 & 9,61 & 7,24 & 10,96 & 14,62 \\
\hline Indice de consommation $\ldots \ldots \ldots \ldots \ldots$ & 11,17 & 8,28 & 6,64 & 7,12 & 16,52 & 9,69 & 7,53 \\
\hline 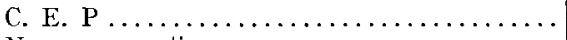 & 1,67 & 1,40 & 0,86 & 1,47 & 0,85 & 0,95 & 0,92 \\
\hline $\mathrm{N}$ retenu, $\mathrm{mg} / \mathrm{j} . \ldots \ldots \ldots \ldots \ldots$ & 32,9 & 54,1 & 67,1 & 55,8 & 17,6 & 40,2 & 59,0 \\
\hline C. U. P.............. & 32,21 & 26,62 & 22,83 & 28,65 & 17,27 & 19,64 & 19,34 \\
\hline Calories retenues $/ \mathrm{j} \ldots \ldots \ldots \ldots$ & 3,41 & 5,76 & 6,66 & 5,80 & 1,69 & 3,57 & 4,86 \\
\hline Coefficient de rétention énergétique.. & 6,60 & 8,89 & 10,42 & 10,42 & 4,53 & 7,11 & 8,79 \\
\hline
\end{tabular}

Analyse de variance :

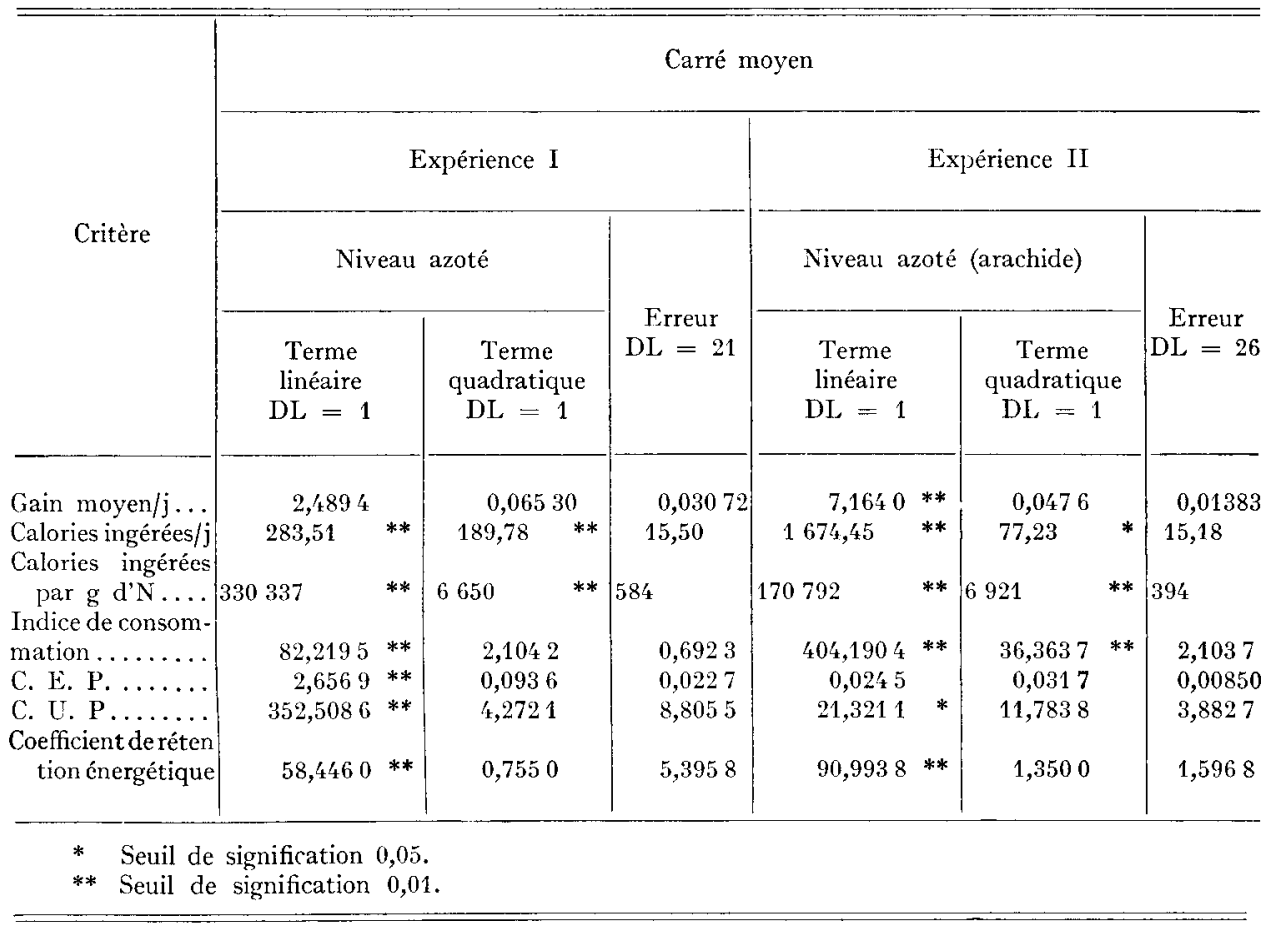


La rétention énergétique et l'indice de consommation sont améliorés dans les deux cas lorsqu'on accroît l'apport azoté.

Il convient de remarquer que les différences constatées à l'issue de périodes aussi longues s'estompent, en raison de la part accrue de l'entretien dans le besoin total, mais elles demeurent significatives aux niveaux considérés.

\section{TABLEAU 4}

Expériences I et II : farine de poisson et tourteau d'arachide à 3 niveaux - Résultals de croissance et de consommation après 8 semaines

\begin{tabular}{|c|c|c|c|c|c|c|c|}
\hline \multirow{2}{*}{ Nature de la protéine } & \multicolumn{3}{|c|}{ Expérience I } & \multicolumn{4}{|c|}{ Expérience II } \\
\hline & \multicolumn{3}{|c|}{ Poisson } & \multirow{2}{*}{$\frac{\text { Poisson }}{1,2}$} & \multicolumn{3}{|c|}{ Arachide } \\
\hline Quantité de protéines $(\mathrm{N} \times 6,25), \mathrm{g} / \mathrm{j}$ & 0,6 & 1,2 & 1,8 & & 0,6 & 1,2 & 1,8 \\
\hline Poids initial (g) $\ldots \ldots \ldots \ldots \ldots \ldots \ldots \ldots$ & 63,2 & 63,2 & 65,9 & 77,8 & 75,7 & 77,4 & 76,8 \\
\hline Poids final $(g) \ldots \ldots \ldots \ldots \ldots \ldots \ldots \ldots$ & 142,0 & 206,9 & 264,9 & 211,8 & 105,5 & 160,3 & 201,9 \\
\hline Gain moyen $/ j(g) \ldots \ldots \ldots \ldots \ldots \ldots$ & 1,41 & 2,56 & 3,55 & $2,1^{\prime} 4$ & 0,54 & 1,51 & 2,27 \\
\hline Ingéré $\sec / \mathrm{j}(\mathrm{g}) \ldots \ldots \ldots \ldots \ldots \ldots \ldots \ldots$ & 10,27 & 12,71 & 13,58 & 11,87 & 7,72 & 10,49 & $12,0^{\prime}$ \\
\hline Calories ingérées $/ \mathrm{j} \ldots \ldots \ldots \ldots \ldots \ldots \ldots \ldots$ & 44,3 & 55,5 & 59,9 & 51,9 & 33,0 & 44,9 & 51,8 \\
\hline Calories ingérées par g d'N . . . . . . . & 429 & 276 & 198 & 268 & 317 & 217 & 167 \\
\hline Protéines consommées p. 100 matière sèche .... & 6,30 & 9,90 & 13,95 & 10,42 & 8,47 & 12,42 & 16,15 \\
\hline Indice de consommation $\ldots \ldots \ldots \ldots$ & 7,30 & 4,96 & 3,84 & 4,87 & 14,24 & 6,96 & 5,34 \\
\hline Coefficient d'efficacité protidique ...... & 2,16 & 2,03 & 1,87 & 1,99 & 0,83 & 1,16 & 1,17 \\
\hline
\end{tabular}

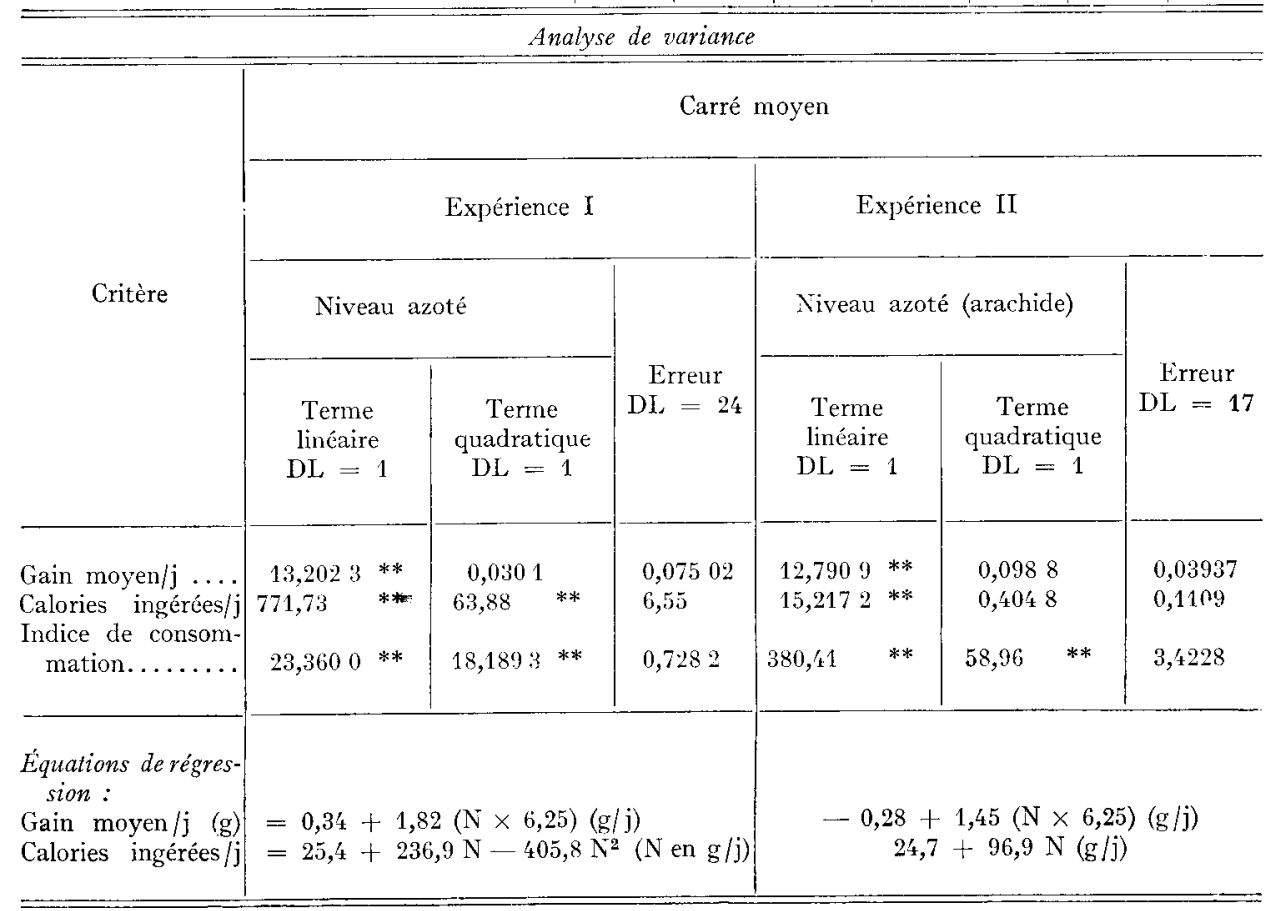


$\left.2^{\circ}\right)$ Résultats après 8 semaines.

La durée des expériences suivantes ayant été fixée à 8 semaines, nous présentons dans les tableaux 4, 5, 6 et 7 les résultats de croissance et de consommation à l'issue de cette période.

Ces 5 expériences réalisent dans le temps un schéma factoriel dans lequel on a utilisé trois sources azotées à trois niveaux. Les résultats obtenus traduisent ainsi l'influence de l'un et l'autre de ces deux facteurs sur la consommation spontanée d'énergie et l'utilisation des matières azotées pour la croissance.

a) Influence du niveau azoté (expériences $I, I I, I I I$ et $V$ ). - L'évolution des résultats de croissance et de consommation est illustrée graphiquement dans la figure I. Pour chacune des protéines étudiées, l'élévation du niveau azoté journalier entraîne une amélioration de la vitesse de croissance et de la consommation d'énergie, ce qui se traduit au niveau de l'organisme par une rétention accrue d'azote et d'énergie. D'une manière générale, la réponse est linéaire pour ces différents critères.

A partir des équations de régression correspondantes (tableaux 4, 5 et 7 ), on déduit l'évolution du rapport énergie/azote et des critères d'efficacité azotée (C. E. P., C. U. P.). Ainsi l'équation donnant la quantité d'énergie ingérée en fonction de la quantité d'azote consommée comprend un terme constant relativement élevé (voisin de 30). Par exemple, dans les lots poisson de l'expérience $V$ (tableau 7), la consommation journalière de calories (I) est donnée par la formule :

$$
\mathrm{I}=38,3+82, \mathrm{I} \mathrm{N} \text { (quantité d'azote comprise entre } 0, \mathrm{I} \text { et } 0,3 \mathrm{~g} / \mathrm{i} \text { ). }
$$

Il en résulte qu'en valeur relative, lorsque la quantité d'azote administrée passe de $0, \mathrm{I}$ à $0,3 \mathrm{~g} / \mathrm{j}$, le rapport énergie/azote qui, dans le cas présent s'écrit : $82, \mathrm{I}+38,3 / \mathrm{N}$, varie dans des limites considérables (entre 483 et 2 I9 dans l'exemple choisi). Il est d'autant plus élevé que le rat ingère moins d'azote ; ceci se conçoit parfaitement en raison de la part accrue de l'énergie utilisée pour l'entretien. De la même façon, le pourcentage de protéines dans la ration sèche augmente avec le niveau azoté, mais moins rapidement que ce dernier.

Les équations donnant le gain de poids et la quantité d'azote retenue en fonction du niveau azoté (tableaux 4,5 et 7 ) comprennent un terme constant dont la valeur est négligeable par rapport aı terme variable. Par voie de conséquence, le C. E. P. et le C. U. P., qui sont les valeurs correspondantes exprimées relativement à l'azote, varient dans des limites assez étroites. Par exemple, si l'on considère de nouveau les lots poisson de l'expérience $V$, le gain de poids et la rétention azotée sont exprimés par les relations :

$$
\begin{gathered}
\text { gain moyen } / \mathrm{j}(\mathrm{g})=0,25+\mathrm{I}, 76(\mathrm{~N} \times 6,25)(\mathrm{g} / \mathrm{j}) \\
\mathrm{N} \text { retenu, } \mathrm{mg} / \mathrm{j}=-2,8+0,37 \mathrm{~N}(\mathrm{mg} / \mathrm{j}) .
\end{gathered}
$$

Les valeurs correspondantes du C. E. P. et du C. U. P. sont alors :

C. E. P. $=\mathrm{I}, 76+0,25 /(\mathrm{N} \times 6,25)$, pour des quantités de protéines $(\mathrm{N} \times 6,25)$ comprises entre 0,6 et $\mathrm{I}, 8 \mathrm{~g} / \mathrm{j}$.

C. U. P. $=37-2,80 / N$, pour des quantités d'azote $(\mathrm{N})$ comprises entre 96 et $288 \mathrm{mg} / \mathrm{j}$.

D'autre part, l'évolution de ces deux coefficients n'est pas la même pour les 3 sources azotées. Dans le cas de la farine de poisson, le C E. P. et le C. U. P. sont 


\section{TABLEAU 5}

Expérience III : gluten de blé à 3 niveaux - Résultats généraux de croissance et de consommation Durée de l'expérience : 57 jours

\begin{tabular}{|c|c|c|c|c|c|c|c|c|}
\hline Sexe & \multicolumn{4}{|c|}{ Mâles } & \multicolumn{4}{|c|}{ Femelles } \\
\hline Source azotée & Poisson & & Gluten & & Poisson & & Gluten & \\
\hline Quantité de protéines $(\mathrm{N} \times 6,25) \mathrm{g} / \mathrm{j}$ & 1,2 & 0,6 & 1,2 & 1,8 & 1,2 & 0,6 & 1,2 & 1,8 \\
\hline Poids initial $(\mathrm{g})$.. & 75,5 & 78,1 & 77,2 & 72,9 & 81,6 & 79,1 & 79,6 & 81,6 \\
\hline Poids final (g) ... & 207,8 & 93,6 & 120,2 & 147,5 & 175,5 & 90,0 & 122,5 & 149,0 \\
\hline Gain moven/i (g) & 2,32 & 0,27 & 0,75 & 1,31 & 1,65 & 0,19 & 0,75 & 1,18 \\
\hline Matière sèche ingérée $/ \mathrm{j}(\mathrm{g}) \ldots \ldots$ & 12,34 & 7,29 & 9,42 & 10,27 & 10,74 & 8,47 & 10,69 & 10,30 \\
\hline Calories ingérées $j[\ldots \ldots \ldots \ldots \ldots$ & 53,6 & 31,3 & $t_{t} 0,8$ & 45,0 & 46,9 & 36,2 & 46,2 & 45,2 \\
\hline Calories ingérées par g d'N ......... & 283 & 335 & 222 & 163 & 249 & 389 & 250 & 165 \\
\hline $\begin{array}{l}\text { Protémes consommées p. } 100 \text { matière } \\
\text { sèche } \ldots \ldots \ldots \ldots \ldots \ldots \ldots \ldots \ldots\end{array}$ & 9,62 & 8,01 & 12,25 & 16,84 & 11,21 & 6,88 & $10,9_{t}^{\prime}$ & 16,76 \\
\hline Indice de consommation $\ldots \ldots \ldots \ldots \ldots$ & 5,34 & 27,61 & 12,60 & 7,85 & 6,67 & 44,73 & 14,48 & 8,71 \\
\hline Coefficient d'efficacité protidique. & 1,96 & 0,46 & 0,65 & 0,76 & 1,39 & 0,33 & $0,6^{\prime} t$ & 0,69 \\
\hline $\mathrm{N}$ retenu, $\mathrm{mg} / \mathrm{j} . \ldots \ldots \ldots \ldots \ldots \ldots \ldots$ & $75,{ }^{\prime}$ & 10,9 & 25,1 & 43,0 & 56,7 & 10,5 & 25,4 & 41,2 \\
\hline Coefficient d'utilisation pratique de & & & & & & & & \\
\hline l'azote................... & 39,77 & 11,60 & 13,70 & 15,44 & 31,89 & 11,37 & 13,68 & 16,02 \\
\hline Calories retenues $/ j$.............. & 6,51 & 1,20 & 2,30 & 3,31 & 4,55 & 0,83 & 2,68 & 3,51 \\
\hline Coefficient de rétention énergétique.. & 12,16 & 3,84 & 5,63 & 7,33 & 9,99 & 2,34 & 5,84 & 7,83 \\
\hline
\end{tabular}

Analyse de variance (lots ghten)

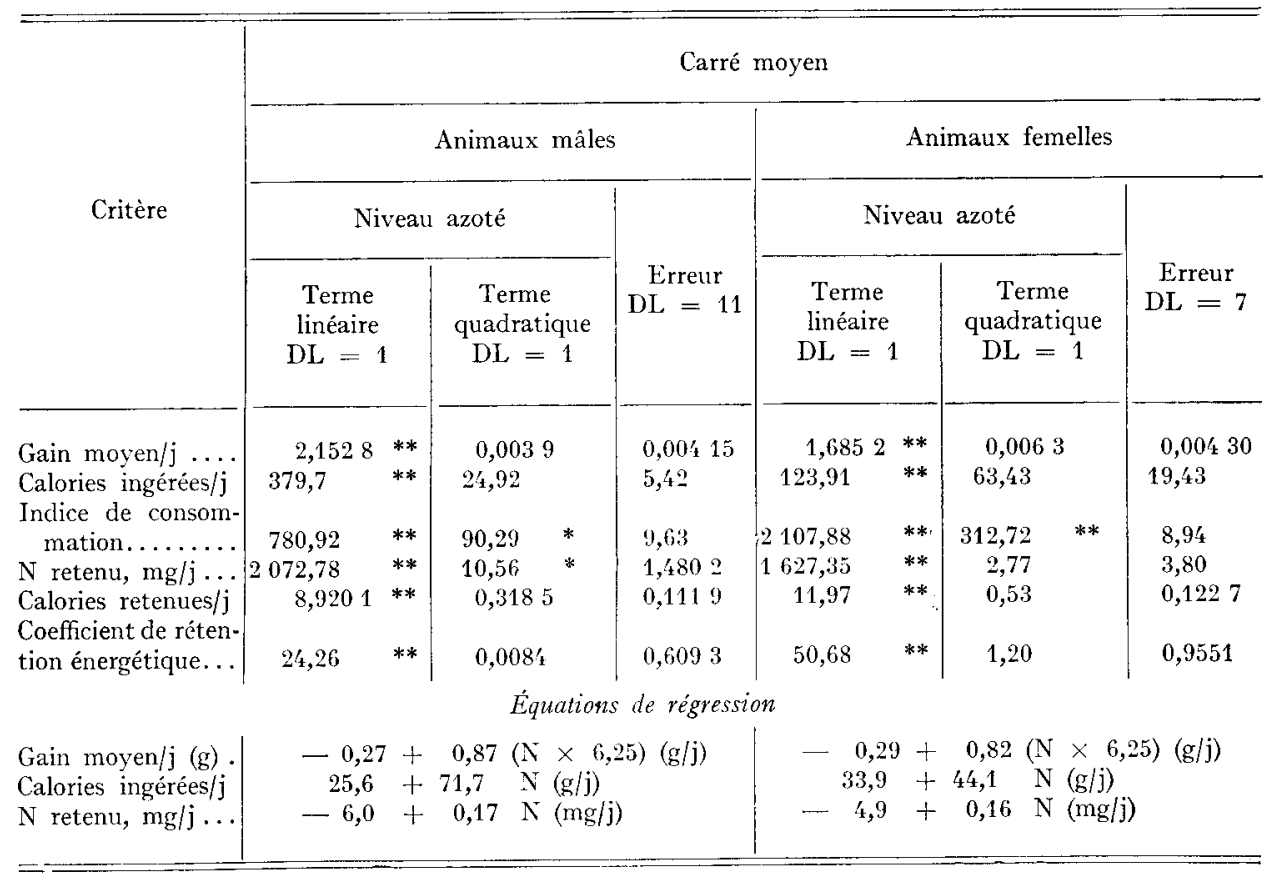


Analyse globale de variance :

\begin{tabular}{|c|c|c|c|c|c|c|c|}
\hline \multirow[b]{2}{*}{$\begin{array}{c}\text { Source de } \\
\text { variation }\end{array}$} & \multirow[b]{2}{*}{ DI } & \multicolumn{6}{|c|}{ Carré moyen (lots gluten) } \\
\hline & & $\begin{array}{c}\text { Gain } \\
\text { moyen } / \mathrm{j}\end{array}$ & $\begin{array}{l}\text { Calories } \\
\text { ingérées/j }\end{array}$ & $\begin{array}{c}\text { Indice de } \\
\text { consommation }\end{array}$ & $\begin{array}{l}\mathrm{N} \text { retenu, } \\
\mathrm{mg} / \mathrm{j}\end{array}$ & $\begin{array}{c}\text { Calories } \\
\text { retenues } / \mathrm{j}\end{array}$ & $\begin{array}{l}\text { Coefficient } \\
\text { de rétention } \\
\text { énergétique }\end{array}$ \\
\hline 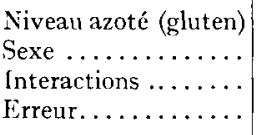 & $\begin{array}{r}2 \\
1 \\
2 \\
18\end{array}$ & 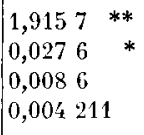 & $\begin{array}{r}329,37 \\
65,79 * \\
16,66 \\
10,87\end{array}$ & $\mid \begin{array}{cc}1496,31 & * * \\
212,28 & * * \\
149,36 & * * \\
9,361 & \end{array}$ & $\mid \begin{array}{c}1 \times 5,, 599^{* *} \\
2,03 \\
2,28 \\
2,3823\end{array}$ & $\begin{array}{r}10,1456 \\
0,0527 \\
0,2902 \\
0,1161\end{array}$ & $\mid \begin{array}{c}35,9570 \\
0,2320 \\
2,1067 \\
0,7438\end{array}$ \\
\hline $\begin{array}{ll}* & \text { Seuil de sign } \\
* * & \text { Seuil de sign }\end{array}$ & $\begin{array}{l}\text { catio } \\
\text { catio }\end{array}$ & $\begin{array}{l}0,05 \\
0,01\end{array}$ & & & & & \\
\hline
\end{tabular}

maximum entre 0,6 et $\mathrm{I}, 2 \mathrm{~g}$ de protéines et diminuent ensuite. Avec le tourteau d'arachide, au contraire, ils n'atteignent leur valeur maximum qu'entre 1,2 et $\mathrm{I}, 8 \mathrm{~g}$ de protéines ; avec le gluten de blé, on obtient une réponse qui reste linéaire dans les limites considérées.

De même que la rétention azotée, la rétention énergétique croît en valeur absolue avec le niveau azoté ; mais en valeur relative par rapport à l'énergie ingérée, elle augmente également d'une manière significative, alors que le C. U. P. a atteint sa valeur optimum. De la même façon, l'indice de consommation diminue lorsque le niveau azoté s'élève.

b) Influence de la nature de la source azotée (expériences IV et V). - La comparaison des 3 sources azotées à niveau constant ( $\mathrm{I}, 2 \mathrm{~g}$ de protéines par jour) a été faite dans l'expérience IV. L'influence de la source azotée est significative au seuil o,or pour l'ensemble des critères (tableau 6 ) et les résultats obtenus sur les animaux mâles et sur les animaux femelles permettent de classer les protéines dans l'ordre de qualité décroissante : farine de poisson, tourteau d'arachide, gluten de blé. Pour une quantité d'azote donnée, la consommation d'énergie et la vitesse de croissance sont d'autant plus élevées que la source azotée est de meilleure qualité ; il en est de même des quantités d'azote et d'énergie retenues dans la carcasse.

L'évolution des critères d'efficacité azotée (C. E. P., C. U. P.) en fonction du niveau d'ingestion est caractéristique de chacune des sources azotées. Ainsi la valeur maximum du C. U. P., dans les limites d'ingestion considérées $(0,6$ à $\mathrm{I}, 8 \mathrm{~g}$ de protéines par jour) est, pour la farine de poisson, 39,20, pour le tourteau d'arachide, $2 \mathrm{I}, 27$, et pour le gluten de blé, $\mathrm{I} 5,44$; de plus, ce maximum est atteint d'autant plus rapidement que la source azotée est de meilleure qualité. Dans l'expérience V, la farine de poisson se révèle de la même façon supérieure au tourteau d'arachide aux 3 niveaux étudiés (tableau 7).

c) Infuence du sexe. - L'utilisation d'animaux mâles et femelles dans les expériences III et IV a permis d'étudier l'influence du sexe sur les résultats de croissance et de consommation (tableaux 5 et 6 ). D'une manière générale, les mâles sont supérieurs aux femelles, mais les différences ne sont pas toujours significatives ;

Annales de Biologie animale. - 1963. 
de même, le sens de l'interaction entre le (ou les) traitements étudiés (source azotée, niveau azoté) et le sexe varie selon les critères. A cet effet, il convient de remarquer que :

- les animaux des deux sexes réagissent de la même façon lorsque l'on fait varier la quantité d'azote ou la nature de la source azotée;
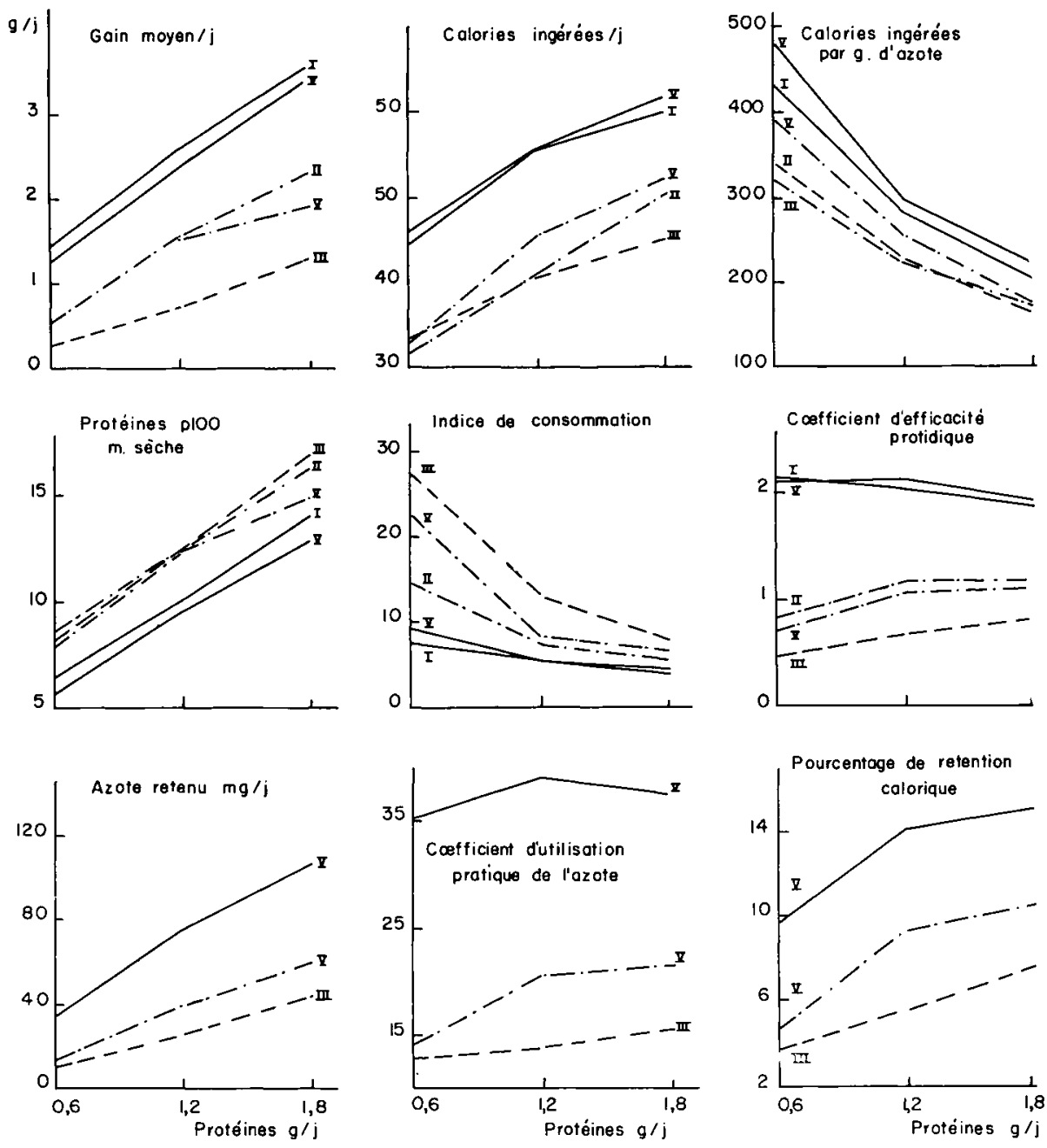

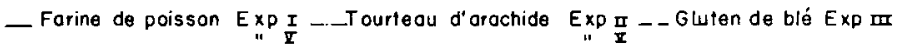

FIG. I. - Infuence du niveau azoté sur les résultats de croissance et de consommation après 8 semaines

- l'influence du sexe est d'autant plus nette que le régime est mieux équilibré. Ceci se conçoit aisément puisque les mâles sont alors susceptibles de mieux extérioriser leurs potentialités de croissance. Par exemple, dans l'expérience IV, l'écart relatif entre mâles et femelles est inférieur à Io p. Ioo dans les lots recevant du tourteau d'arachide ou du gluten de blé, alors qu'il est de 25 p. roo dans le lot rece- 


\section{TABLEAU 6}

Expérience $I V$ : niveau azolé constant - Résultats généraux de croissance et de consommation Durée de l'expérience : 57 jours

\begin{tabular}{|c|c|c|c|c|c|c|}
\hline Sexe & & Mâles & & & Femelles & \\
\hline $\begin{array}{c}\text { Source azotée } \\
\text { Quantité de protéines/j (g) }\end{array}$ & $\begin{array}{c}\text { Poisson } \\
1,2\end{array}$ & $\begin{array}{c}\text { Arachide } \\
1,2\end{array}$ & $\begin{array}{c}\text { Gluten } \\
1,2\end{array}$ & $\begin{array}{c}\text { Poisson } \\
1,2\end{array}$ & $\begin{array}{c}\text { Arachide } \\
1,2\end{array}$ & $\begin{array}{l}\text { Gluten } \\
\quad 12\end{array}$ \\
\hline $\begin{array}{l}\text { Poids initial }(g) \ldots \ldots \ldots \ldots \ldots \ldots \ldots \ldots \ldots \\
\text { Poids final }(g) \ldots \ldots \ldots \ldots \ldots \ldots \ldots \ldots \ldots \ldots \\
\text { Gain moyen } / \mathrm{j}(\mathrm{g}) \ldots \ldots \ldots \ldots \ldots \ldots \ldots \ldots \ldots \\
\text { Matière sèche ingérée } / \mathrm{j}(\mathrm{g}) \ldots \ldots \ldots \ldots \ldots \ldots \ldots \\
\text { Calories ingérées } / \mathrm{j} \ldots \ldots \ldots \ldots \ldots \ldots \ldots \ldots\end{array}$ & $\begin{array}{c}75,4 \\
209,8 \\
2,36 \\
12,40 \\
53,9\end{array}$ & $\begin{array}{c}75,6 \\
150,1 \\
1,31 \\
10,38 \\
44,5\end{array}$ & $\begin{array}{c}75,2 \\
120,6 \\
0,80 \\
8,56 \\
37,2\end{array}$ & $\begin{array}{c}73,2 \\
176,4 \\
1,81 \\
11,54 \\
50,3\end{array}$ & $\begin{array}{r}73,0 \\
1 / 42,0 \\
1,21 \\
10,92 \\
46,8 \\
\end{array}$ & $\begin{array}{c}73,6 \\
115,5 \\
0,73 \\
8,98 \\
39,0\end{array}$ \\
\hline 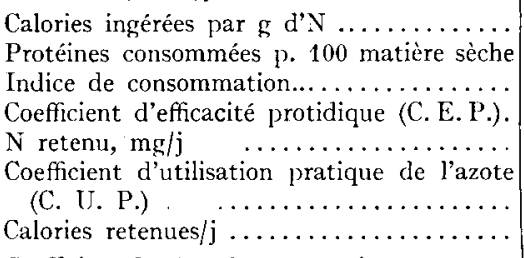 & $\begin{array}{c}285 \\
10,03 \\
5,27 \\
1,98 \\
75,6 \\
\\
39,82 \\
6,27\end{array}$ & $\begin{array}{r}226 \\
11,90 \\
7,95 \\
1,06 \\
44,0\end{array}$ & $\begin{array}{c}201 \\
13,57 \\
11,00 \\
0,69 \\
25,6\end{array}$ & $\begin{array}{c}265 \\
10,31 \\
6,37 \\
1,52 \\
59,1\end{array}$ & $\begin{array}{c}237 \\
11,3^{\prime} \prime \\
9,1^{\prime} \\
0,98 \\
40,9\end{array}$ & $\begin{array}{c}212 \\
12,89 \\
12,51 \\
0,61 \\
25,6\end{array}$ \\
\hline Coefficient de rétention énergétique ........ & 11,72 & 7,62 & 6,39 & 10,12 & 7,37 & 5,50 \\
\hline
\end{tabular}

Les moyennes non réunies par une ligne sont différentes au seuil 0,05 ; celles qui sont soulignées ensemble ne sont pas significativement différentes (test de KEULS-NEWMaN).

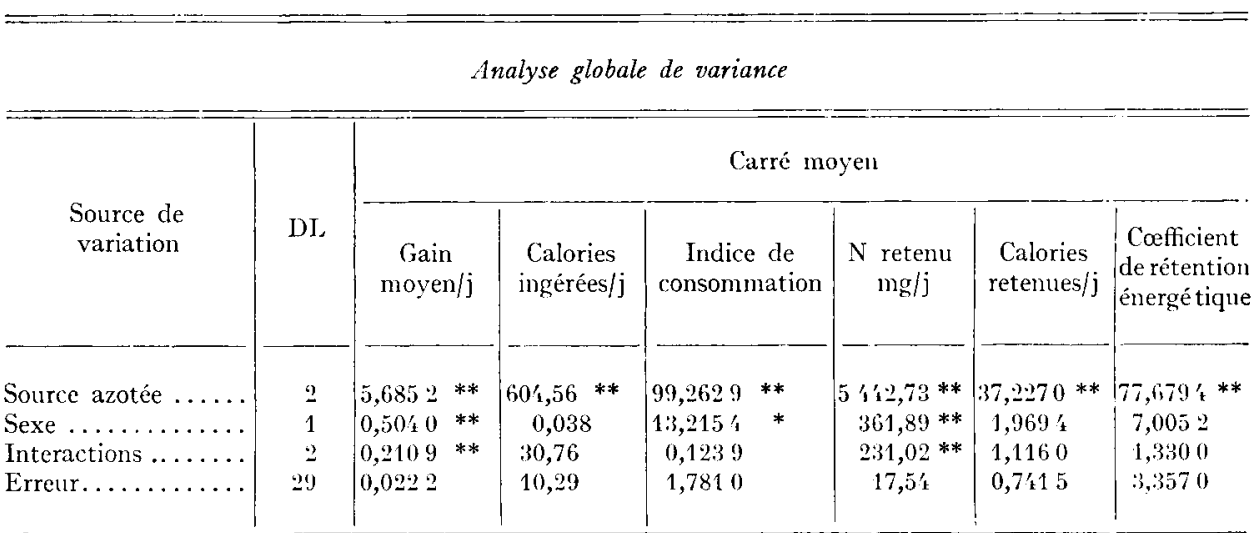

* Seuil de signification 0,05 .

** Seuil de signification 0,01 .

vant de la farine de poisson. De même, dans l'expérience III, utilisant le gluten de blé, il n'existe pas de différence significative entre les mâles et les femelles.

d) Reproductibilité des résultats. - La comparaison d'une expérience à l'autre des lots témoins recevant $\mathrm{I}, 2 \mathrm{~g}$ de protéines de poisson par jour fait ressortir une grande constance dans les résultats, ce qui est d'autant plus remarquable que les 


\section{TABLEAU 7}

Expérience $V$ : farine de poisson et tourteau d'arachide à 3 niveaux - Résultats généraux de croissance tt de consommation - Durée de l'expérience : 56 jours

\begin{tabular}{|c|c|c|c|c|c|c|}
\hline \multirow{2}{*}{ Nature de la protéine } & \multicolumn{3}{|c|}{ Poisson } & \multicolumn{3}{|c|}{ Arachide } \\
\hline & 0,6 & 1,2 & 1,8 & 0,6 & 1,2 & 1,8 \\
\hline Poids initial $(g) \ldots \ldots \ldots \ldots \ldots \ldots \ldots$ & 71,3 & 70,3 & 69,4 & 72,6 & 70,1 & 71,4 \\
\hline Poids final $(\mathrm{g}) \ldots \ldots \ldots \ldots \ldots \ldots \ldots \ldots$ & 140,9 & 211,9 & 257,5 & 96,7 & 140,4 & 177,3 \\
\hline Gain moyen par jour $(\mathrm{g}) \ldots \ldots \ldots \ldots \ldots$ & 1,24 & 2,36 & 3,36 & 0,43 & 1,25 & 1,89 \\
\hline Matière sèche ingérée/j $(\mathrm{g}) \ldots \ldots \ldots \ldots \ldots$ & 10,65 & 12,77 & 14,10 & 7,88 & 9,61 & 11,79 \\
\hline 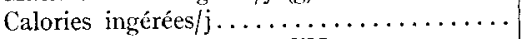 & 45,7 & 55,1 & 61,5 & 33,4 & 40,8 & 50,2 \\
\hline Calories ingérées par g d'N ........... & 483 & 291 & 219 & $3+7$ & 217 & 181 \\
\hline Protéines consommées p. 100 mat. sèche.. & 5,63 & 9,41 & 12,56 & 7,67 & 12,29 & 14,85 \\
\hline 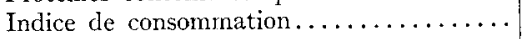 & 8,93 & $5,0^{\prime}$ & 4,20 & 22,47 & 7,69 & 6,25 \\
\hline 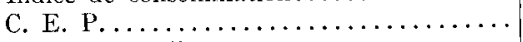 & 2,10 & $2,11^{\prime}$ & 1,91 & 0,71 & 1,06 & 1,09 \\
\hline $\mathrm{N}$ retenu, $\mathrm{mg} / \mathrm{j} \ldots \ldots \ldots \ldots \ldots \ldots \ldots \ldots$ & 33,6 & 74,1 & 105,5 & 13,7 & 38,6 & 58,9 \\
\hline 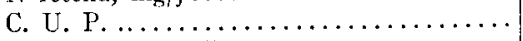 & 35,53 & 39,20 & 37,57 & 14,33 & 20,61 & 21,27 \\
\hline Calories retenues $/ j \ldots \ldots \ldots \ldots \ldots \ldots \ldots$ & 4,40 & 7,73 & 9,22 & 1,56 & 3,78 & 5,11 \\
\hline Cofficient de rétention énergétique ....... & 9,69 & $1 / 4,00$ & 14,96 & 4,73 & 9,26 & 10,27 \\
\hline
\end{tabular}

Analyse de vartance

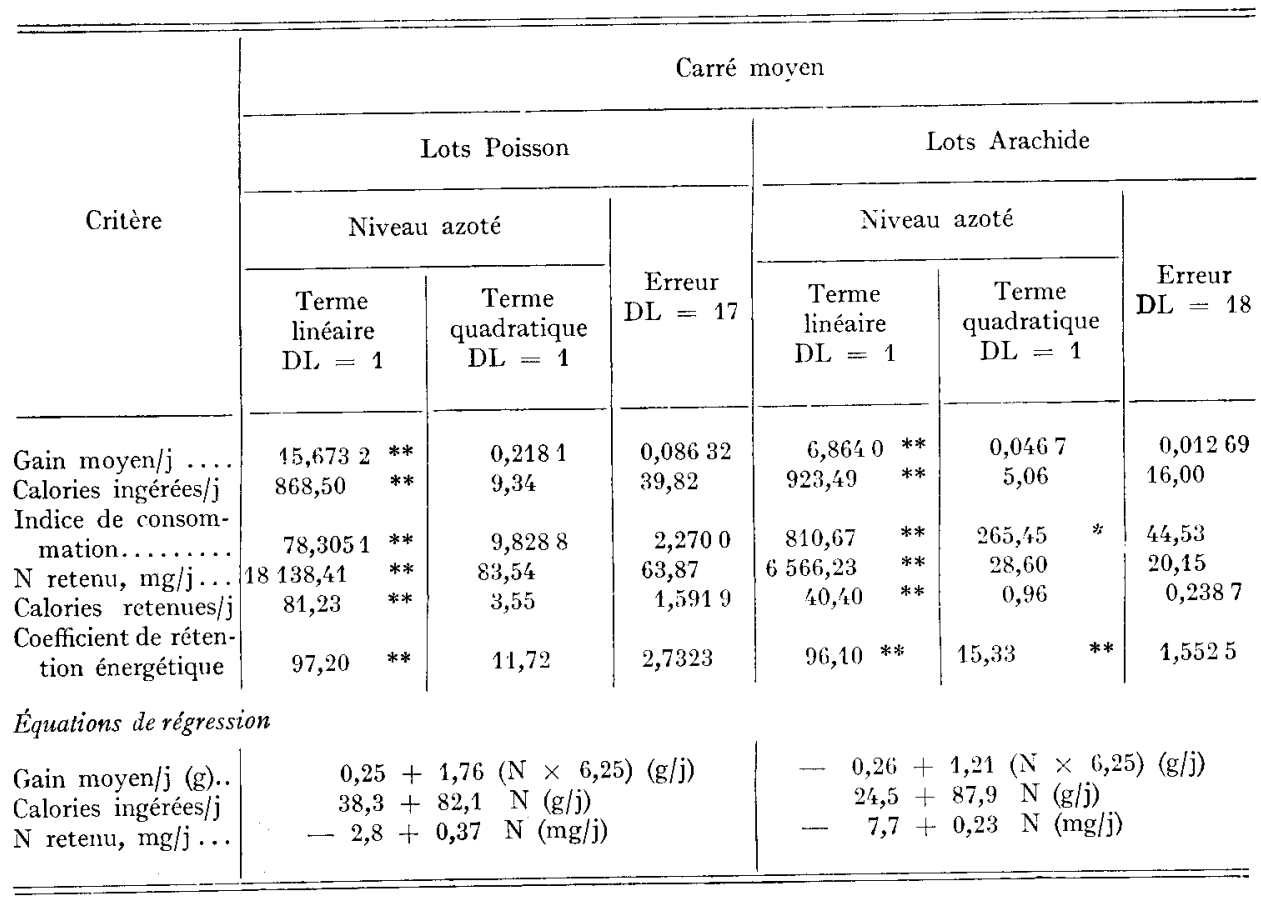


Analyse globale de variance

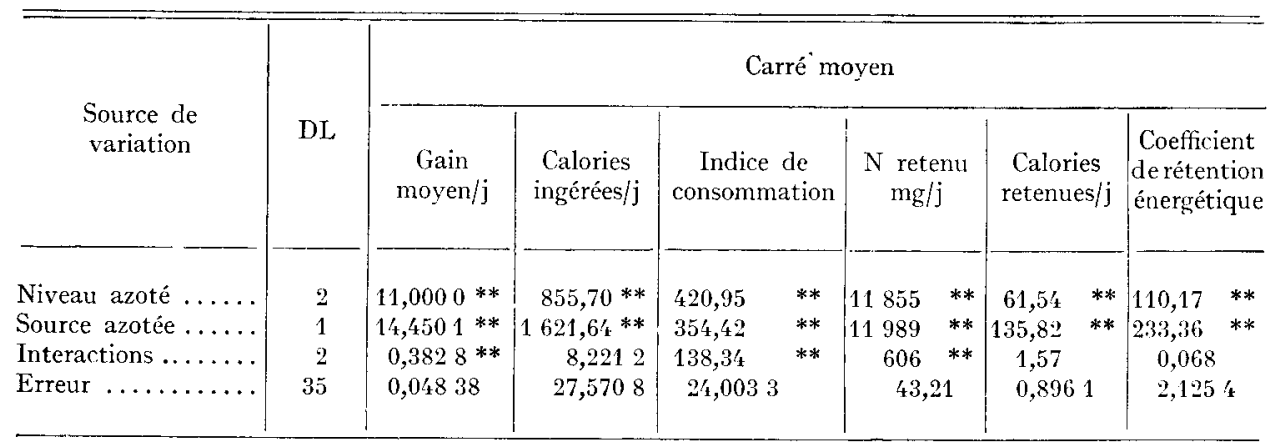

* Seuil de signification 0,05 .

** Seuil de signification 0,01 .

5 expériences ont été réalisées à des époques différentes : dans ces lots, le gain moyen journalier varie dans les limites de 2,32 à $2,56 \mathrm{~g}$, soit une marge de variation de Io $\mathrm{p}$. Ioo seulement; de même la consommation journalière d'énergie reste compris e entre $5 \mathrm{I}, 9$ et 55 , I calories. On peut faire la même constatation pour les autres lots représentant la répétition des traitements dans le temps. Ajoutons à cela que les courbes montrant l'évolution des différents critères en fonction de la quantité de protéines, qu'il s'agisse du poisson ou de l'arachide, se superposent parfaitement d'une expérience à l'autre (fig. I).

\section{B. - Evolution des critères au cours de la croissance}

La durée des expériences I et II a été portée respectivement à I40 et I25 jours de manière à suivre la consommation spontanée d'énergie chez le rat tout au long de sa croissance. A cet effet, il a été procédé à un découpage de la période totale en périodes de I4 jours ; pout chacune de ces dernières a été établi un tableau de résultats individuels par critère : gain moyen journalier, énergie ingérée par jour, indice de consommation, coefficient d'efficacité protidique, calories ingérées par $\mathrm{g}$ d'azote, pourcentage de protéines dans la matière sèche. Les valeurs moyennes de ces différents critères au cours des périodes successives sont représentées graphiquement dans la figure 2 .

\section{Io) Vitesse de croissance.}

Les courbes de croissance des lots poisson, arachide et gluten des expériences I, II, III et IV sont rapportées dans la figure 3. Les gains de poids correspondants par quinzaine sont maximum dès les deux premières quinzaines et diminuent ensuite progressivement au fur et à mesure de la croissance, de même que leurs écarts d'un lot à l'autre (fig. 2). L'ajustement de ces courbes de croissance suivant la méthode préconisée par BRODY (I945), Forbes et RAO (I959), conduit à l'obtention de relations du type :

$$
\log (\mathrm{A}-\mathrm{P})=\log \mathrm{b}-\mathrm{kt}
$$




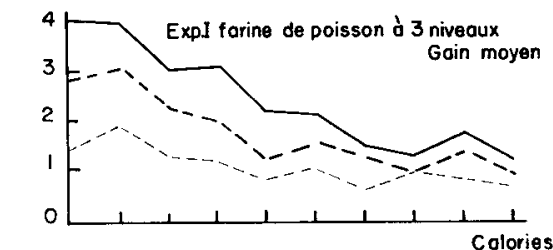

Exp.I tourteau d'arachide ò 3 niveoux journalier $g / j$
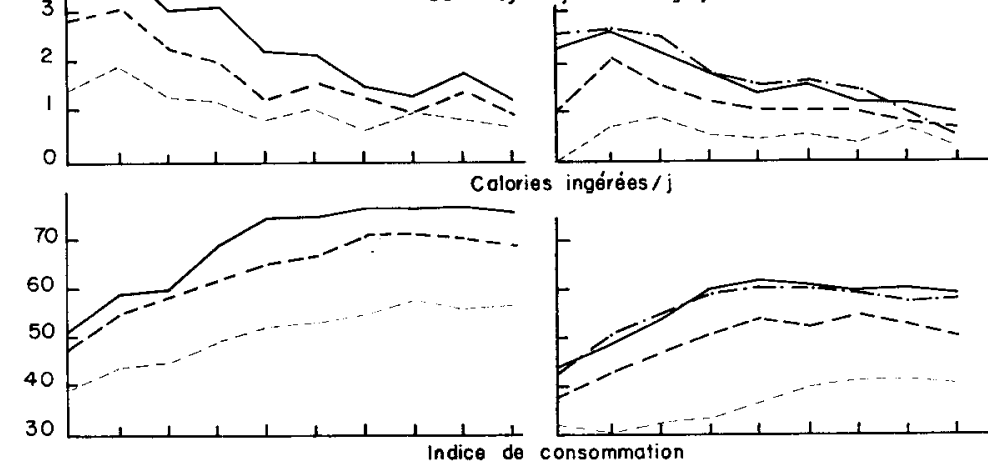

Calories ingérées $/ \mathrm{j}$
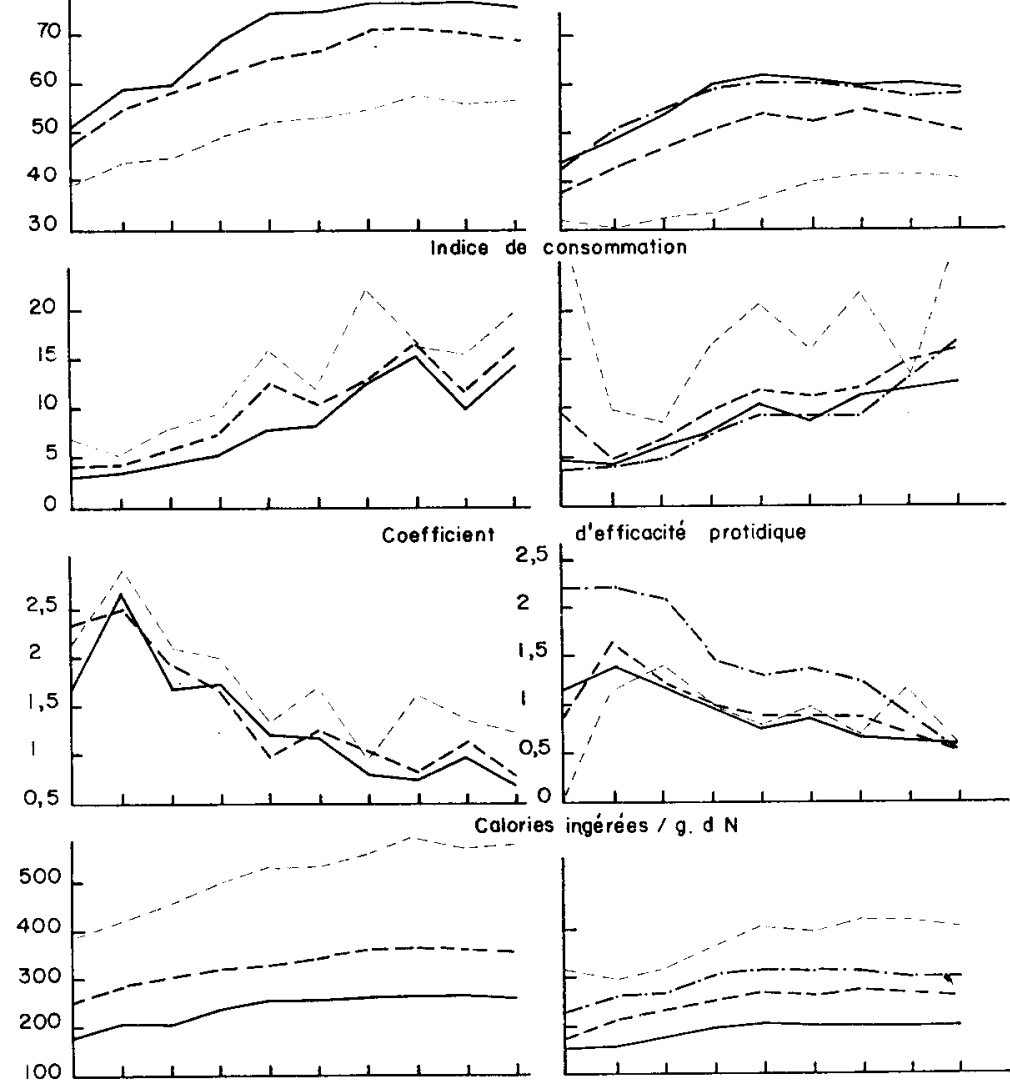

, 5

d'efficocité protidique

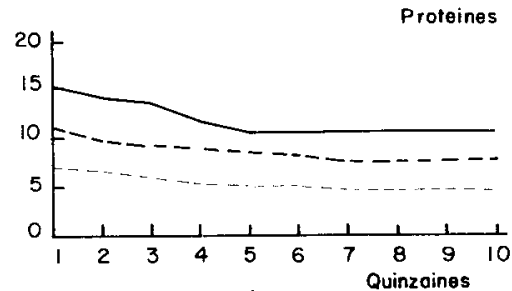

p.100 matière sèche
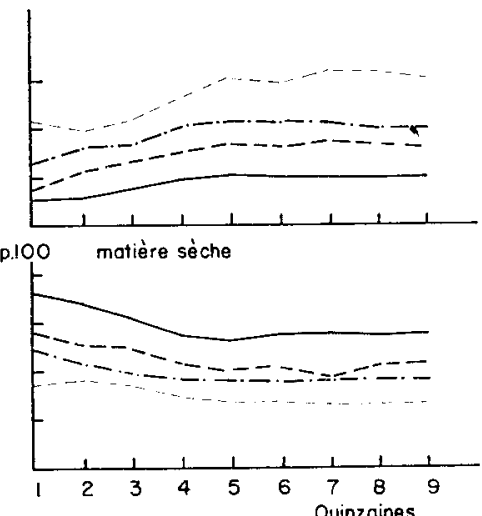

Source azotée quantité

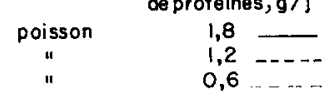

Source azotée quantité

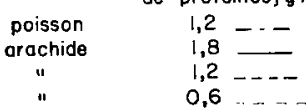

FIG. 2. - Évolution des crilères par quinzaine (expériences $I$ et $I I$ ) 
$t$ étant le nombre de jours depuis le début de l'expérience, $\mathrm{P}$ le poids des animaux en $\mathrm{g}, \mathrm{A}$ le poids maximum à l'âge adulte qui a été fixé à $500 \mathrm{~g}$ par observation sur la souche utilisée, $b$ et $k$ des constantes ajustées par la méthode des moindres carrés.
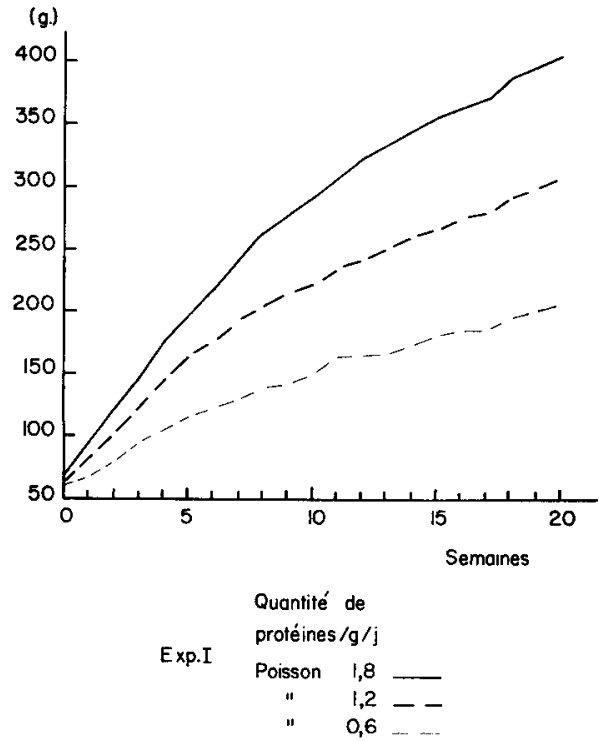

Exp.III

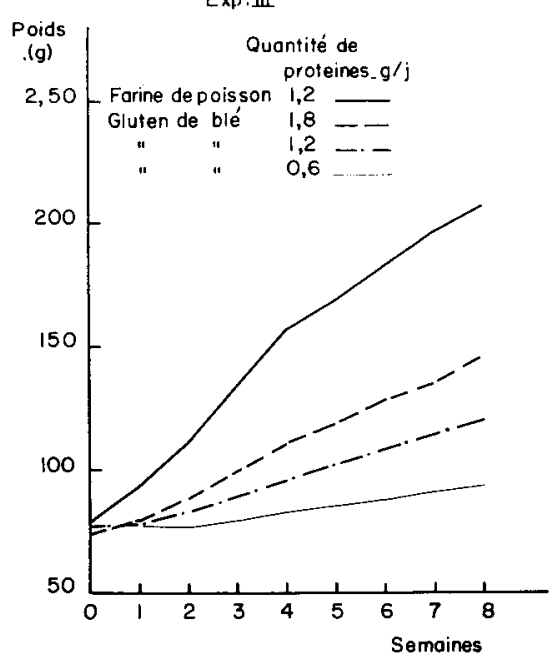

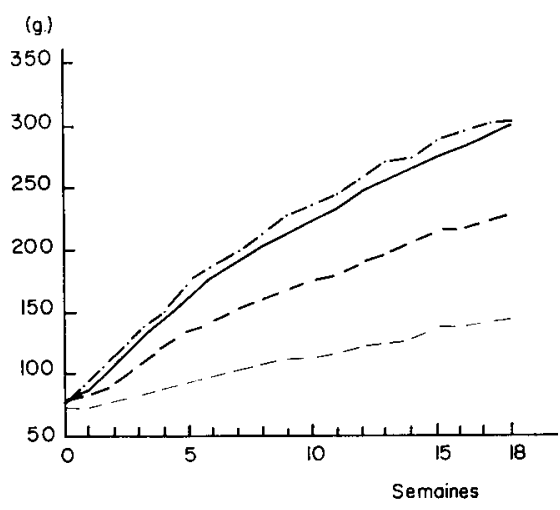

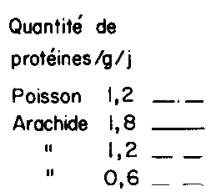

Exp. IV

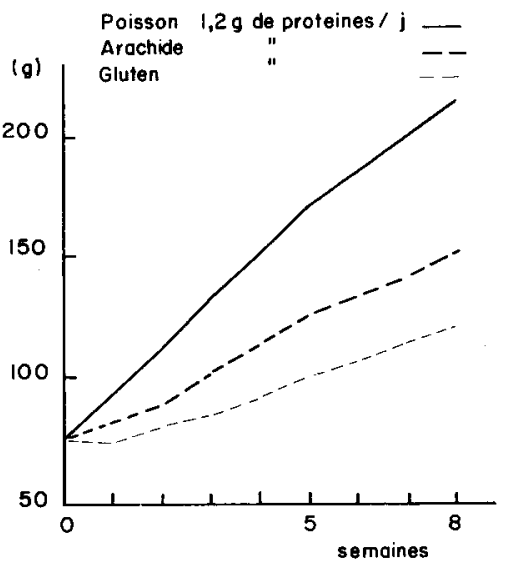

FIG. 3. - Courbes de croissance (animaux máles)

L'étude de la régression de $\log (500-\mathrm{P})$ sur $t$ donne une série de droites de régression (fig. 4) dont les équations sont rapportées dans le tableau 8 ; le coefficient de corrélation est dans tous les cas très voisin de l'unité. 
Ces relations peuvent également s'écrire sous la forme exponentielle. Par exemple, la croissance des animaux du lot poisson recevant $\mathrm{I}, 8 \mathrm{~g}$ de protéines par jour, dans l'expérience I, est représentée par l'équation :

qui peut s'écrire :

$$
\log (500-\mathrm{P})=2,62887-0,00457 t
$$

$$
\log (500-\mathrm{P})=\log 425-0,00457 t
$$

ou, après transformation en logarithmes népériens :

$$
\begin{gathered}
\mathrm{I}_{1}(500-\mathrm{P})=\mathrm{L} 425-0,00457 \times 2,3026-t \\
\mathrm{I} \frac{500-\mathrm{P}}{425}=30,0105 t
\end{gathered}
$$

d'où la relation exponentielle :

$$
\begin{aligned}
& 500-\mathrm{P}=425 \cdot e^{-0,0105 t} \\
& \mathrm{P}=500-425 \cdot e^{-0,0105 t}
\end{aligned}
$$
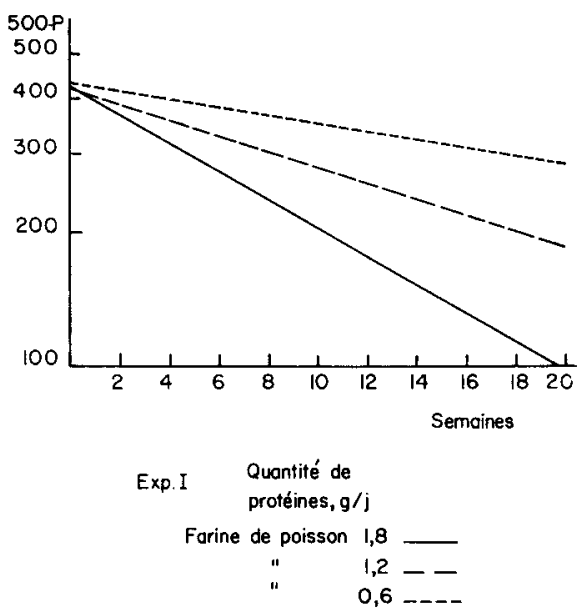
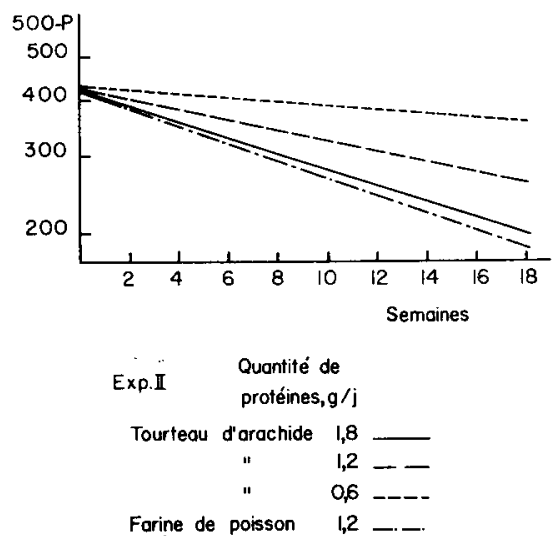

FIG. 4. - Représentation logarithmique de la croissance (expériences I et II)

La constante $b=425$ représente le complément à 500 du poids initial puisque, pour $t=0, \mathrm{P}=500-b$.

Chaque courbe de croissance est ainsi caractérisée par une valeur définie du coefficient $k$.

La vitesse de croissance $d \mathrm{P} / d t$ au temps $t$ est obtenue en différenciant l'équation (3) :

$$
\begin{gathered}
d \mathrm{P} / d t=425 \times 0,0105 . e^{-0,0105 t} \\
d \mathrm{P} / d t=4,46 . e^{-0,0105 t} .
\end{gathered}
$$

De même, en différenciant l'équation (2) :

$$
\begin{gathered}
\frac{d \mathrm{P}}{500-\mathrm{P}}=0,0105 . d t \\
\text { soit }: d \mathrm{P} / d t=0,0105(500-\mathrm{P}) \\
d \mathrm{P} / d t=5,25-0,0105 \mathrm{P} .
\end{gathered}
$$


En définitive, la vitesse de croissance peut être considérée comme une fonction exponentielle du temps $t$ (équation 4 ) ou une fonction linéaire du poids $\mathrm{P}$ au temps $t$ (équation 5).

$\left.2^{\circ}\right)$ Consommation d'énergie, rapport calories/azote, protéines p. Ioo matière sèche (fig. 2):

La consommation d'énergie par quinzaine augmente régulièrement avec l'âge, mais au bout d'un certain temps, elle atteint un plateau, d'autant plus rapidement que l'intensité de la croissance est plus forte. Par exemple, dans le cas de la farine de poisson, ce maximum est obtenu pratiquement dès la cinquième quinzaine pour $\mathrm{I}, 8 \mathrm{~g}$ de protéines par jour, et à la huitième quinzaine seulement pour $0,6 \mathrm{~g}$ de protéines par jour.

L'évolution est la même en ce qui concerne le nombre de calories par g d'azote, qui augmente avec la quantité de protéines ; pour une quantité de protéines donnée $(\mathrm{I}, 2 \mathrm{~g})$, il est également plus élevé avec le poisson qu'avec l'arachide. Il est intéressant de noter que les rats composent des régimes dont la teneur en protéines ne varie pratiquement plus à partir de la cinquième quinzaine.

$\left.3^{\circ}\right)$ Indice de consommation (fig. 2) :

L'indice de consommation évolue dans le sens inverse du gain moyen journalier ; à un âge donné, il augmente lorsque la quantité d'azote diminue.

\section{$\left.4^{\circ}\right)$ Coefficient d'efficacité protidique :}

L'évolution du C. E. P. se déduit également de celle du gain moyen journalier; d'une manière générale, les variations en fonction du niveau azoté sont les mêmes aux différents stades de la croissance. Dans le cas du poisson, le C. E. P. est maximum dès la deuxième quinzaine, puis décroît régulièrement; les valeurs les plus élevées sont obtenues au niveau azoté le plus faible $(0,6 \mathrm{~g})$. Dans le cas de l'arachide, le C. E. P. est également maximum entre la deuxième et la troisième quinzaine, mais sa valeur est pratiquement la même aux trois niveaux azotés tout au long de la croissance.

Par ailleurs, il est possible de calculer le C. E. P. d'après les équations donnant la vitesse de croissance ( $\mathrm{dP} / d t$ ) en fonction du temps ou du poids (tableau 8 ). Par exemple, dans le cas de la farine de poisson, on obtient les équations suivantes :

En fonction du temps $t$

En fonction du poids $P$

$\begin{array}{rlll}\text { à } 1,8 \mathrm{~g} \text { de protéines } / \mathrm{j} & \text { C.E.P. }=2,48 \cdot \mathrm{e}^{-0,0105 t} & \text { C.E.P. }=2,92-0,0058 \mathrm{P} \\ 1,2 \mathrm{~g} \text { de protéines } / \mathrm{j} & \text { C.E.P. }=2,03 \cdot \mathrm{e}^{-0,0058 t} & \text { C.E.P. }=2,42-0,0048 & \mathrm{P} \\ 0,6 \mathrm{~g} \text { de protéines } / \mathrm{j} & \text { C.E.P. }=2,08 \cdot \mathrm{e}^{-0,0029 t} & \text { C.E.P. }=2,42-0,0048 & \mathrm{P}\end{array}$

De même, dans le cas du tourteau d'arachide :

$\begin{array}{rlll}\text { à } 1,8 \mathrm{~g} \text { de protéines } / \mathrm{j} & \text { C.E.P. }=1,38 \cdot \mathrm{e}^{-0,0059 t} & \text { C.E.P. }=1,64-0,0033 & \mathrm{P} \\ 1,2 \mathrm{~g} \text { de protéines } / \mathrm{j} & \text { C.E.P. }=1,30 \cdot \mathrm{e}^{-0,0037 t} & \text { C.E.P. }=1,54-0,0031 & \mathrm{P} \\ 0,6 \mathrm{~g} \text { de protéines } / \mathrm{j} & \text { C.E.P. }=1,07 \cdot \mathrm{e}^{-0,0015 t} & \text { C.E.P. }=1,25-0,0025 & \text { P }\end{array}$

Comme on peut le constater, la diminution du C. E. P. suit une allure exponentielle en fonction du temps et une allure linéaire en fonction du poids; d'autre part, cette diminution du C. F. P. est d'autant plus rapide que le niveau azoté est plus élevé et la source azotée de meilleure qualité. 
TABLEAU 8

Evolution de la croissance en fonction du temps

\begin{tabular}{|c|c|c|c|c|c|c|c|}
\hline \multirow{2}{*}{$\begin{array}{l}\text { Expé- } \\
\text { rience }\end{array}$} & \multirow{2}{*}{$\begin{array}{l}\text { Nature } \\
\text { de la } \\
\text { protéine }\end{array}$} & \multirow{2}{*}{$\begin{array}{l}\text { Quan- } \\
\text { tité de } \\
\text { proté- } \\
\text { ines } g / j\end{array}$} & \multirow{2}{*}{$\begin{array}{l}\text { Equation de } \\
\text { régression log } \\
(500-\mathrm{P})=\end{array}$} & \multirow{2}{*}{$\begin{array}{l}\text { Coeffi- } \\
\text { cient de } \\
\text { corréla- } \\
\text { tion } r\end{array}$} & \multirow{2}{*}{$\begin{array}{c}\text { Valeur de } \mathrm{P} \text { en } \\
\text { fonction de } t \\
\mathrm{P}=\end{array}$} & \multicolumn{2}{|c|}{ Vitesse de croissance $\mathrm{dP} / \mathrm{d} t,(\mathrm{~g} / \mathrm{j})$} \\
\hline & & & & & & $\begin{array}{l}\text { en fonction de } \mathrm{t} \\
\mathrm{d} \mathrm{P} / \mathrm{d} t=\end{array}$ & $\begin{array}{c}\text { en fonction de } \mathrm{P} \\
\mathrm{dP} / \mathrm{d} t=\end{array}$ \\
\hline \multirow{3}{*}{ I } & Poisson & 1,8 & $2,62887-0,00 \div 57 t$ & $-0,957$ & $500-{ }_{4} 25 \cdot \mathrm{e}^{-0,0105 t}$ & $4,46 \cdot \mathrm{e}^{-0,0105 t}$ & $5,25-0,0105 \mathrm{P}$ \\
\hline & id. & 1,2 & $2,62386-0,00254 t$ & $-0,997$ & $500-42 \mathrm{~L} \cdot \mathrm{e}^{-0,0058 t}$ & $2,44 \cdot \mathrm{e}^{-0,0058 t}$ & $2,90-0,0058 \mathrm{P}$ \\
\hline & id. & 0,6 & $2,63364-0,00126 t$ & $-0,992$ & $500-430 \cdot e^{-0,0029 t}$ & $1,25 \cdot \mathrm{e}^{-0,0020 t}$ & $1,45-0,0029 \mathrm{P}$ \\
\hline \multirow{4}{*}{ II } & Poisson & 1,2 & $2,61979-0,00275 t$ & $\longrightarrow 0,997$ & $500-417 \cdot \mathrm{e}^{-0,0083 t}$ & $2,63 \cdot \mathrm{e}^{-0,0063 t}$ & $3,15-0,0063 \mathrm{P}$ \\
\hline & Arachide & 1,8 & $2,62462-0,00256 t$ & $-0,999$ & $500-421 \cdot \mathrm{e}^{-\mathbf{0}, 0059 t}$ & $2,48 \cdot \mathrm{e}^{-0,0059 t}$ & $2,95-0,0059 \mathrm{P}$ \\
\hline & id. & 1,2 & $2,62552-0,00161 t$ & $-0,996$ & $500-422 \cdot \mathrm{e}^{-0,0037 t}$ & $1,56 \cdot \mathrm{e}^{-0,0037 t}$ & $1,85-0,0037 \mathrm{P}$ \\
\hline & id. & 0,6 & $2,63361-0,00066 t$ & $-0,996$ & $500-430 \cdot \mathrm{e}^{-0,0015 t}$ & $0,6 t \cdot e^{-0,0015 t}$ & $0,75-0,0015 \mathrm{P}$ \\
\hline
\end{tabular}

Notons que les termas constants de $d \mathrm{P} / d t$ varient pratiquement dans les mêmes proportions ( $I: 2: 3)$ que le niveau azoté ; c'est ce qui explique les faibles variations du C. E. P. en fonction du niveau azoté, au même âge ou à un poids défini.

\section{C. - Relation entre la consommation spontanée d'énergie et le poids}

L'analyse détaillée des tableaux de résultats à 8 semaines montre qu'à niveau de croissance égal, la consommation spontanée d'énergie est la même quels que soient l'origine de la source azotée et son niveau; c'est le cas des lots " poisson-0,6 », " arachide-I,2 " et " arachide-I,8 ». De plus, dans ces deux derniers lots, les consommations d'énergie sont à tout moment les mêmes pour des vitesses de croissance qui sont également identiques (fig. 2). On peut donc supposer qu'il existe une relation étroite entre l'ingéré calorique et le niveau de croissance. A cet effet, dans une précédente publication (HENRY et RERAT, I962), il a été procédé, après transformation logarithmique des données, à l'étude de la régression de l'ingestion journalière d'énergie (I) sur le poids moyen pondéré (P) par animal et par quinzaine, dans un même intervalle de poids $\left(60-I_{5} 0 \mathrm{~g}\right)$ pour les différents lots. Une série d'équations linéaires, de la forme $\log \mathrm{I}=a+b \log \mathrm{P}$, a été obtenue ; ces équations sont pratiquement les mêmes d'un lot à l'autre au sein d'une même expérience, tant par la valeur de l'ordonnée à l'origine $(a)$ que par celie de la pente $(b)$. Si l'on considère par exemple les lots poisson et arachide de l'expérience $V$, on obtient:

$$
\begin{gathered}
\text { pour le poisson, } \log \mathrm{I}=0,55 \mathrm{I} 74+0,554 \log \mathrm{P}, \\
\text { pour l'arachide, } \log \mathrm{I}=0,48223+0,56 \mathrm{I} \log \mathrm{P} .
\end{gathered}
$$

Les relations précédentes peuvent encore s'écrire sous la forme exponentielle: $\mathrm{I}=a \mathrm{P}^{b}$, soit :

$$
\begin{array}{ll}
\text { pour le poisson, } I=3,56 & \mathrm{P}^{\mathbf{0 , 5 5 4}}, \\
\text { pour l'arachide, } \mathrm{I}=3,06 & \mathrm{P}^{\mathbf{0 , 5 6 1}} .
\end{array}
$$




\section{TABLEAU 9}

Équations de régression donnant l'ingéré énergétique moyen journalier (1) en fonction du poids moyen $\mathrm{p}^{2 / 3}$ et du gain moyen journalier, par période de 2 semaines (expérience $\mathrm{V}$ )

\begin{tabular}{|c|c|c|c|}
\hline $\begin{array}{l}\text { Nature de } \\
\text { la source } \\
\text { azotée }\end{array}$ & $\begin{array}{l}\text { Quantité } \\
\text { de protéines } \\
(\mathrm{g} / \mathrm{j})\end{array}$ & $\begin{array}{l}\text { Nombre } \\
\text { de } \\
\text { données }\end{array}$ & $\begin{array}{l}\text { Équations de régression } \\
\mathrm{I} \text { : calories ingérées } / \mathrm{j} ; \mathrm{P}^{2 / 3}, \mathrm{~g} \cdot ; \Delta \mathrm{P}: \text { gain moyen, } \mathrm{g} / \mathrm{j}\end{array}$ \\
\hline Poisson & $\begin{array}{l}1,8 \\
1,2 \\
0,6\end{array}$ & $\begin{array}{l}28 \\
24 \\
28\end{array}$ & $\begin{array}{lll}\mathrm{I}= & 0,8+1,63( \pm 0,21)^{(1)} & \mathrm{P}^{2 / 3}+3,50( \pm 1,82)(1) \Delta \mathrm{P} \\
\mathrm{I}=--5,2+1,73( \pm 0,46) & \mathrm{P}^{2 / 3}+5,22( \pm 4,54) & \Delta \mathrm{P} \\
\mathrm{I}=-1,0+2,02( \pm 0,53) & \mathrm{P}^{2 / 3}+1,57( \pm 1,47) & \Delta \mathrm{P}\end{array}$ \\
\hline Arachide & $\begin{array}{l}1,8 \\
1,2 \\
0,6\end{array}$ & $\begin{array}{l}28 \\
32 \\
24\end{array}$ & 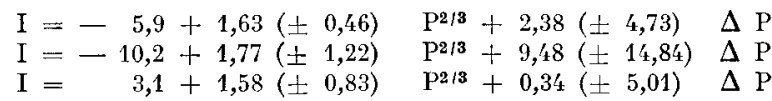 \\
\hline
\end{tabular}

Signification de la régression

\begin{tabular}{|c|c|c|c|}
\hline Lot & Source de variation & DL & Carré moyen \\
\hline Poisson $\quad-1,8$ & $\begin{array}{l}\mathrm{P}^{2 / 3} \\
\Delta \mathrm{P} \\
\text { Erreur }\end{array}$ & $\begin{array}{r}1 \\
1 \\
25\end{array}$ & $\begin{array}{c}3113,92 * * \\
174,96 * * \\
11,74\end{array}$ \\
\hline Poisson $-1,2$ & $\begin{array}{l}\mathrm{P}^{2 / 3} \\
\Delta \mathrm{P} \\
\text { Erreur }\end{array}$ & $\begin{array}{r}1 \\
1 \\
25\end{array}$ & $\begin{array}{c}2473,70 * * \\
218,98 * \\
38,50\end{array}$ \\
\hline Poisson $-0,6$ & $\begin{array}{l}\mathrm{P}^{2 / 3} \\
\Delta \mathrm{P} \\
\text { Erreur }\end{array}$ & $\begin{array}{r}1 \\
1 \\
25\end{array}$ & $\begin{array}{c}109,72 * * \\
15,80 \\
17,91\end{array}$ \\
\hline Arachide $-1,8$ & $\begin{array}{l}\mathrm{P}^{2 / 3} \\
\Delta \mathrm{P} \\
\text { Erreur }\end{array}$ & $\begin{array}{r}1 \\
1 \\
25\end{array}$ & $\begin{array}{c}14 / 2,96 * * \\
30,11 \\
27,61\end{array}$ \\
\hline Arachide $\rightarrow 1,2$ & $\begin{array}{l}\mathrm{P}^{2 / 3} \\
\Delta \mathrm{P}^{\mathrm{P}} \\
\text { Erreur }\end{array}$ & $\begin{array}{r}1 \\
1 \\
29\end{array}$ & $\begin{array}{c}1035,16 * * \\
201,00^{* *} \\
11,76\end{array}$ \\
\hline Arachide $-0,6$ & $\begin{array}{l}\mathrm{P}^{2 / 3} \\
\Delta \mathrm{P} \\
\text { Erreur }\end{array}$ & $\begin{array}{r}1 \\
1 \\
21\end{array}$ & $\begin{array}{c}160,48 * * \\
0,19 \\
10,21\end{array}$ \\
\hline
\end{tabular}

(1) Intervalles de confiance estimés au seuil 0,05 .

** Seuil de signification : 0,01 .

* Seuil de signification 0,05 . 
Autrement dit, la consommation journalière d'énergie est proportionnelle au poids élevé à une puissance fixe (voisine de 0,5 dans l'intervalle de poids $60-5^{\circ} \mathrm{g}$ ), quelles que soient la quantité et la nature des protéines administrées.

On peut se demander si l'on n'obtiendrait pas une relation plus fidèle en rapportant la consommation d'énergie (I) à la "taille métabolique " ( $\mathrm{P}^{3 / 4}$ ou $\mathrm{P}^{2 / 3}$ ) et au gain de poids $(\Delta P)$, ainsi que l'ont proposé d'autres auteurs pour d'autres espèces (BYERLY, I94 I, pour les volailles ; GARRETT, MEYER et LOFGREEN, I959, pour les ovins et les bovins; CoOp, I962, pour les ovins). La relation obtenue est alors de la forme :

$$
\mathrm{I}=a \cdot \mathrm{P}^{b}+c \cdot \Delta \mathrm{P} .
$$

Ayant choisi a priori pout l'exposant du poids $(b)$ la valeur $2 / 3$, nous avons étudié, dans l'expérience $V$, pour chaque lot, la régression de l'ingéré énergétique moyen journalier par quinzaine sur le poids moyen correspondant élevé à la puissance $2 / 3$ et le gain de poids journalier. Les 6 équations sont rapportées dans le tableau 9. D'après l'analyse statistique des résultats, il apparaît que le terme $\mathrm{P}^{2 / 3}$ est dans tous les cas hautement significatif, tandis que le terme $\Delta \mathrm{P}$ n'atteint le seuil de signification que dans les lots " poisson - I, 8 ", " poisson - I, 2 " et " arachide $-I, 2$ ".

D'une manière générale, l'influence du gain de poids sur le niveau de consommation est d'autant plus marquée que le niveau de croissance est plus élevé, mais de toute façon l'intervalle de confiance de la constante $c$ est relativement élevé par rapport à sa valeur estimée. Dans ces conditions, nous pouvons négliger dans les équations ci-dessus le terme $c . \Delta \mathrm{P}$, de même que l'ordonnée à l'origine, et il restela relation : $\mathrm{I}=a \mathrm{P}^{b}$ précédemment trouvée. Remarquons d'ailleurs que les deux variables $\mathrm{P}$ et $\Delta \mathrm{P}$, ne sont pas indépendantes; la relation ingéré-poids tient compte en réalité de l'intensité de croissance.

\section{D. - Relation entre la consommation spontanée d'énergie et la rétention azotée}

Les calculs précédents ont montré qu'il existe une relation constante entre la consommation spontanée d'énergie et le poids, donc le niveau de croissance ; or, ce dernier est lui-même proportionnel à la quantité de tissu musculaire synthétisée par l'animal, c'est-à-dire à la quantité d'azote fixée. C'est pourquoi, pour mieux préciser le phénomène, nous avons étudié directement l'évolution de la consommation d'énergie après 8 semaines en fonction de la quantité d'azote retenue dans les tissus, pour chacune des protéines aux 3 niveaux et pour les 3 protéines à niveau constant (expériences III, IV et V). Les calculs de régression, dont les résultats ont été rapportés par ailleurs (RERAT, HENRY, et JACQUOT, I962) ont conduit à l'obtention d'une série d'équations linéaires (tableau ro). Les droites représentatives correspondantes (fig. 5) sont pratiquement confondues, tant par leurs ordonnées à l'origine que par leurs pentes; la régression linéaire est dans tous les cas hautement significative. Autrement dit, la consommation spontanée d'énergie est directement proportionnelle à la quantité d'azote fixée par l'animal pour fabriquer ses tissus de croissance ; le rat ingère une quantité constante d'énergie par $\mathrm{g}$ d'azote supplémentaire retenu (environ 300 calories). Il est à noter cependant que dans les lots poisson, qui ont réalisé une croissance plus rapide que ceux à l'arachide ou au gluten, la pente de la droite de régression a tendance à être plus faible. 


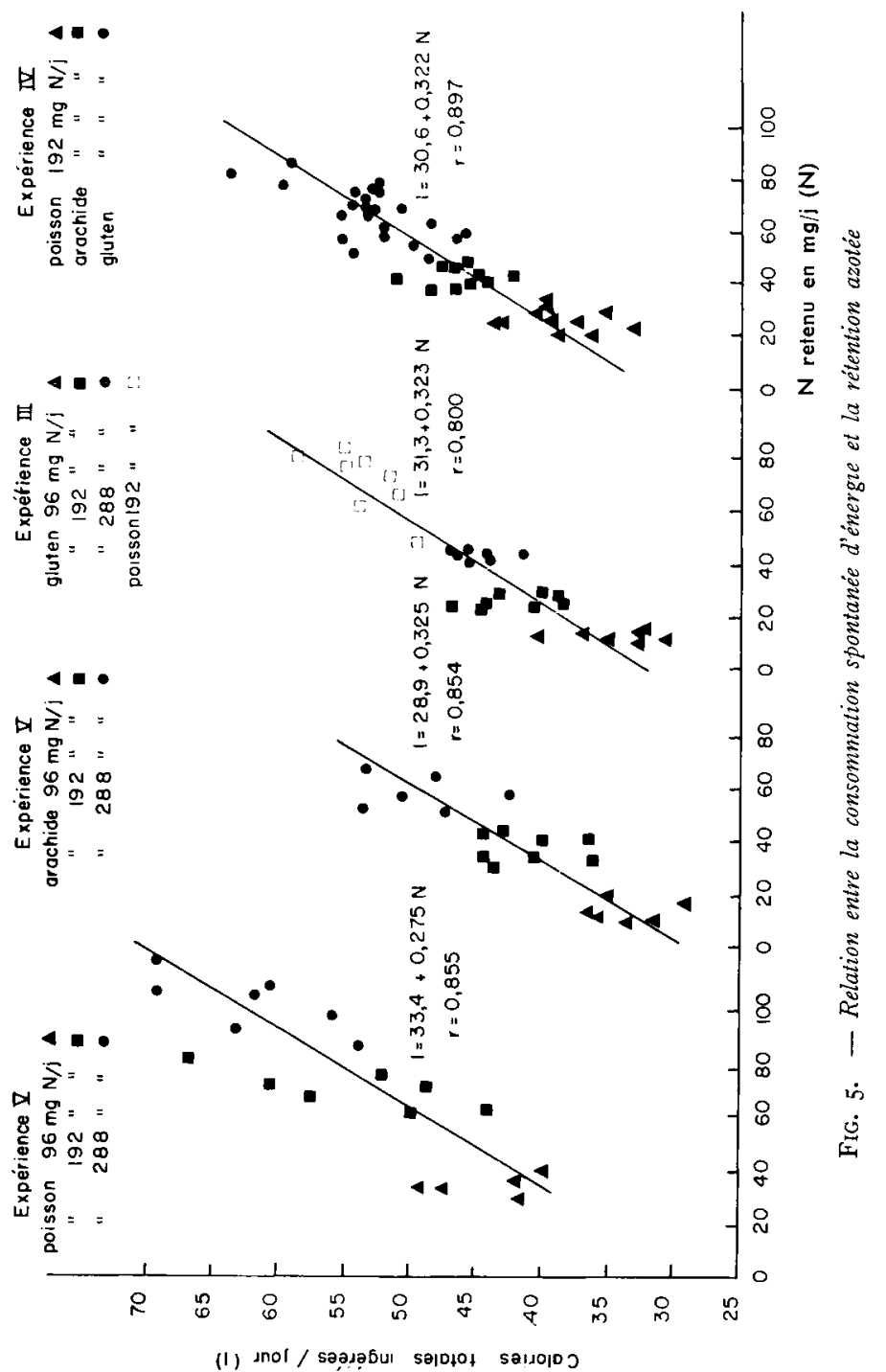


TABI,EAU IO

Évolution de la consommation spontanée d'énergie en fonction de la rétention azotée

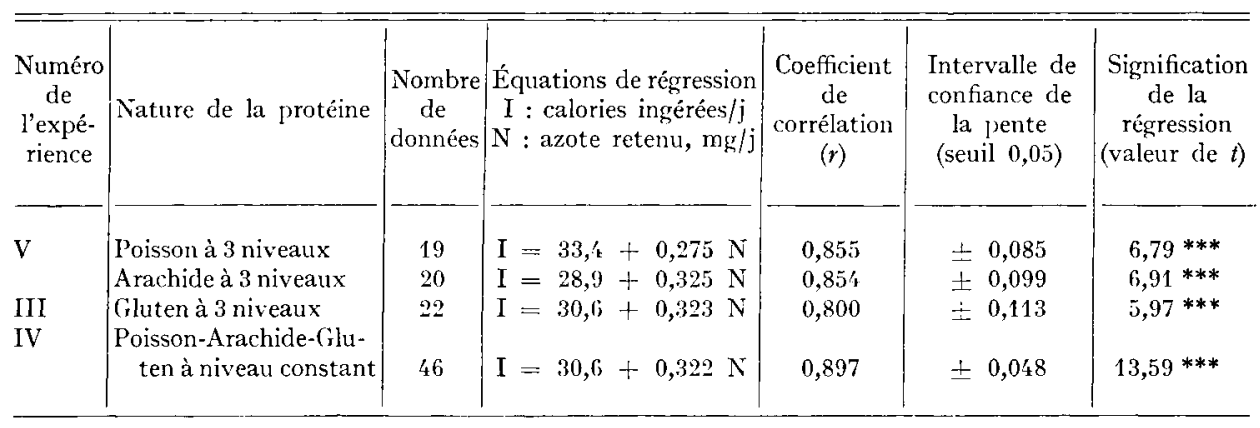

*** : seuil de signification 0,001 .

\section{E. - Composition corporelle}

\section{I0) Après I4o jours (expérience I) et I25 jours (expérience II)}

L'examen des résultats de composition corporelle des lots poisson (tableau II) ne révèle aucune différence significative après $r 40$ jours, malgré des écarts importants dans le poids final (2 Io à $370 \mathrm{~g}$ ). Il en est de même des teneurs en eau et en lipides dans les lots arachide, tandis que le pourcentage de protéines augmente avec le niveau azoté. Dans l'expérience II, on constate que le lot témoin poisson est plus riche en lipides que les lots arachide; la différence est significative au seuil o,05.

\section{$\left.2^{\circ}\right)$ Après 8 semaines}

Les résultats de composition corporelle après 8 semaines sont rapportés dans le tableau I2. On n'observe aucune différence significative entre les lots des expériences III et IV. Dans l'expérience V, au contraire, l'évolution des teneurs en eau, protéines et lipides est différente selon qu'il s'agit du poisson ou de l'arachide. Dans le cas du poisson, la teneur en protéines de la carcasse croît linéairement avec le niveau azoté ; dans le cas de l'arachide, elle est pratiquement la même aux 3 niveaux. Quant au pourcentage de lipides, il n'est pas influencé par le niveau azoté ; mais il est plus élevé dans les lots au poisson que dans ceux à l'arachide.

Il convient de remarquer que les différences de composition corporelle sont imputables pour une part at1x écarts de poids en fin d'expérience. Afin de tenir compte de ce facteur de variation, nous avons représenté graphiquement, en coordonnées logarithmiques, les quantités d'azote et de lipides contenues dans la carcasse en fonction du poids à l'abattage. D'une manière générale, les points se répartissent sur une même droite, ce qui semble indiquer que le développement des tissus musculaire et adipeux est régi par le même phénomène d'allométrie dans les différents lots (fig.6). A partir de ces données, nous avons établi une série d'équations (tableau I3), donnant les quantités finales d'azote et de lipides en fonction du poids des animaux à l'abat- 
TABI_EAU II

Expériences $I$ et II : farine de poisson et tourteau d'arnchide à 3 niveaux. Résultats de composition corporelle après $\mathrm{I} 4 \mathrm{O}$ jours (expérience $I$ ) et $\mathbf{1} 25$ jours (expérience II)

\begin{tabular}{|c|c|c|c|c|c|c|c|}
\hline $\begin{array}{l}\text { Expé- } \\
\text { rience }\end{array}$ & $\begin{array}{c}\text { Nature de la } \\
\text { protéine }\end{array}$ & $\begin{array}{l}\text { Quantités } \\
\text { de } \\
\text { protéines/j } \\
\text { (g) }\end{array}$ & $\begin{array}{c}\text { Poids final } \\
\text { (g) }\end{array}$ & Eau \% & Cendres \% & Protéines $\%$ & Lipides \% \\
\hline I & $\begin{array}{l}\text { Poisson } \ldots \ldots \ldots \\
\text { Poisson } \\
\text { Poisson }\end{array}$ & $\begin{array}{l}1,8 \\
1,2 \\
0,6\end{array}$ & $\begin{array}{l}367,7 \\
312,1 \\
213,1\end{array}$ & $\begin{array}{l}59,37 \\
58,46 \\
60,51\end{array}$ & $\begin{array}{l}3,{ }^{\prime}, 6 \\
3,3^{\prime} \\
3,6^{\prime}\end{array}$ & $\begin{array}{l}19,31 \\
18,89 \\
18,29\end{array}$ & $\begin{array}{l}17,86 \\
19,31 \\
17,58\end{array}$ \\
\hline II & $\begin{array}{l}\text { Poisson } \ldots \ldots \ldots \\
\text { Arachide. . . . . } \\
\text { Arachide. . . . } \\
\text { Arachide. . . . }\end{array}$ & $\begin{array}{l}1,2 \\
1,8 \\
1,2 \\
0,6\end{array}$ & $\begin{array}{l}301,5 \\
294,7 \\
230,3 \\
143,3\end{array}$ & $\begin{array}{l}58,59 \\
61,56 \\
61,59 \\
62,58\end{array}$ & $\begin{array}{l}3,43 \\
3,46 \\
3,56 \\
4,09\end{array}$ & $\begin{array}{l}19,05 \\
20,25 \\
19,64 \\
18,96\end{array}$ & $\begin{array}{l}18,93 \\
14,73 \\
15,21 \\
14,37\end{array}$ \\
\hline
\end{tabular}

Analyse de variance

\begin{tabular}{|c|c|c|c|c|c|c|}
\hline \multirow{4}{*}{ Critère } & \multicolumn{6}{|c|}{ Carré moyen } \\
\hline & \multicolumn{3}{|c|}{ Expérience I } & \multicolumn{3}{|c|}{ Expérience II } \\
\hline & \multicolumn{2}{|c|}{ Niveau azoté } & \multirow[b]{2}{*}{$\begin{array}{c}\text { Erreur } \\
\mathrm{DL}=21\end{array}$} & \multicolumn{2}{|c|}{ Niveau azoté } & \multirow[b]{2}{*}{$\begin{array}{c}\text { Erreur } \\
\text { DI }=26\end{array}$} \\
\hline & $\begin{array}{c}\text { Terme } \\
\text { linéaire } \\
D L=1\end{array}$ & $\begin{array}{c}\text { Terme } \\
\text { quadratique } \\
\mathrm{DL}=1\end{array}$ & & $\begin{array}{c}\text { Terme } \\
\text { linéaire } \\
\mathrm{DL}=1\end{array}$ & $\begin{array}{c}\text { Terme } \\
\text { quadratique } \\
\mathrm{DL}:=\mathbf{1}\end{array}$ & \\
\hline Protéines p. $100 \ldots \ldots \ldots \ldots$. & 2,6114 & $\begin{array}{r}4,7502 \\
17,5813\end{array}$ & $\begin{array}{r}2,0288 \\
3,3055\end{array}$ & $8,3205 * *$ & 0,0107 & 0,3417 \\
\hline Lipides p. $100 \ldots \ldots \ldots \ldots \ldots$ & 1,3514 & 17,5813 & 34,3955 & 0,8120 & $3,18 / 8$ & $6,37 \times 3$ \\
\hline
\end{tabular}

** Seuil de signification 0,01 .

tage. L'examen détaillé de ce tableau fait ressortir une grande similitude des équations d'une expérience à l'autre. A ce sujet, il y a lieu de faire quelques commentaires :

Dans 1'expérience $V$, nous avons considéré séparément les lots poisson et arachide. Il est à remarquer que 3 animaux du lot "Poisson-o,6 " s'écartent de la droite générale, tant du point de vue azote que du point de vue lipides ; c'est ce qui explique que les pentes des droites de régression sont dans ce cas légèrement différentes (plus élevée pour l'azote et plus faible pour les lipides).

Les variations individuelles sont beaucoup plus importantes pour les lipides 
que pour l'azote, d'où les valeurs plus élevées de l'intervalle de confiance des pentes des droites de régression correspondantes.

Les quantités d'azote et de lipides contenues dans la carcasse peuvent être considérées comme des fonctions exponentielles du poids :

Pour l'azote :

\begin{tabular}{|c|c|c|c|c|c|c|}
\hline expérience & III : $\mathrm{N}$ & $(e n g)$ & $=$ & 0,336 & $P^{1,005}$ & (en $g)$ \\
\hline expérience & IV : $\mathrm{N}$ & - & $=$ & 0,436 & $\mathrm{Pl}, 053$ & - \\
\hline expérience & $V: N$ & 一 & $=$ & 0,410 & $\mathrm{P}^{1,037}$ & \\
\hline \multicolumn{7}{|c|}{ Pour les lipides: } \\
\hline xpérience & III : M.G. & (en g) & $=$ & 0,153 & $\mathrm{P}^{\mathrm{1}, 132}$ & $(e n g)$ \\
\hline expérience & IV : M.G. & - & $=$ & 0,188 & $P^{1,167}$ & \\
\hline expérience & V: M.G. & - & $=$ & 0,151 & $\mathrm{P}^{1,156}$ & \\
\hline
\end{tabular}

L'identité de ces relations ne fait aucun doute. Étant donné que l'exposant du poids est supérieur à I dans les deux cas, on en déduit que les pourcentages de protéines et de lipides dans la carcasse augmentent avec le poids, lui-même fonction

\section{TABLEAU I2}

Expériences $111, I V$, et $V$ : résultats de composition corporelle après 8 semaines

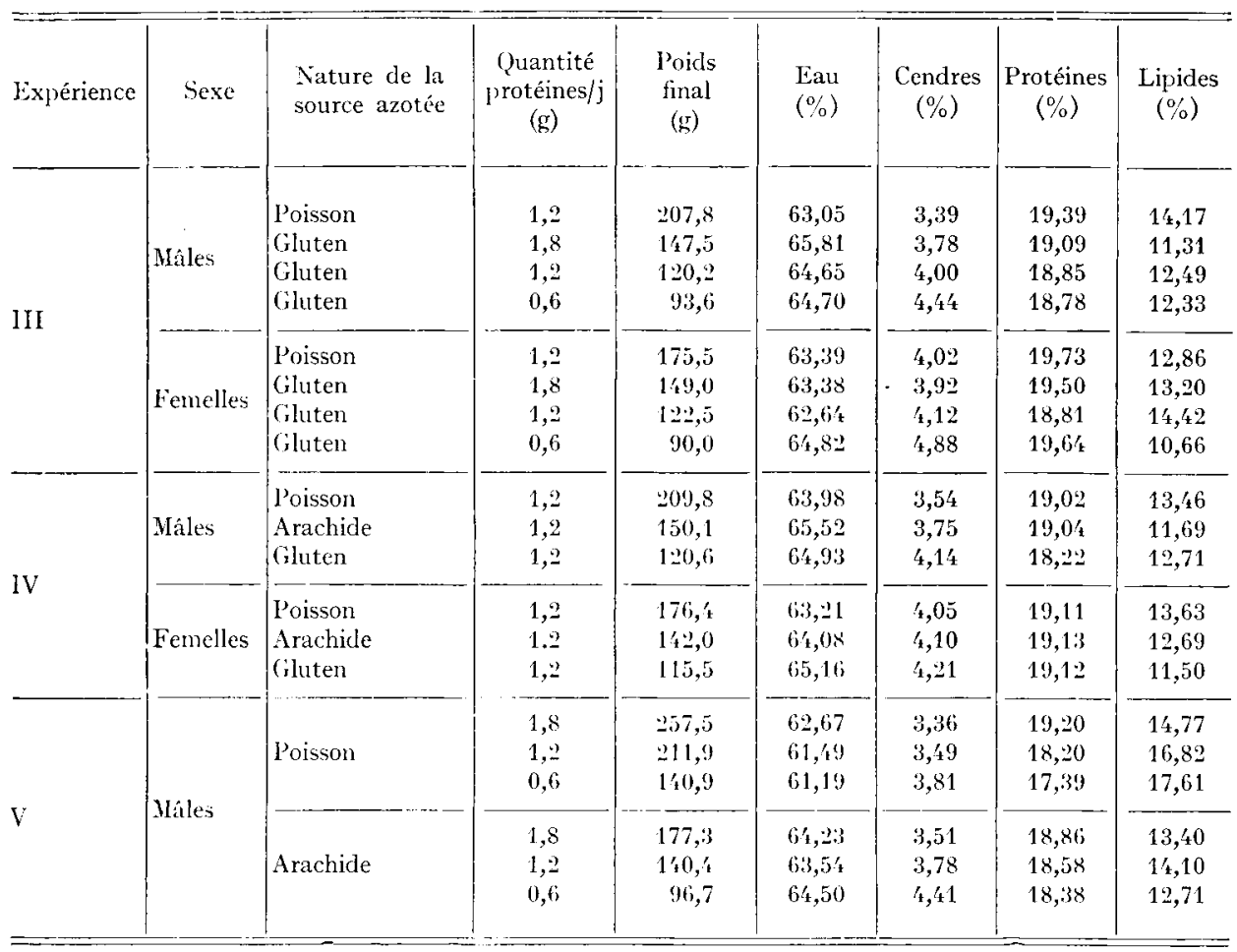


Analyse de variance

Expérience 111

Expérience $I V$

\begin{tabular}{|c|c|c|c|c|c|c|c|}
\hline \multirow{2}{*}{$\begin{array}{l}\text { Source de } \\
\text { variation }\end{array}$} & \multirow{2}{*}{$\mathrm{DL}$} & \multicolumn{2}{|c|}{ Carré moyen } & \multirow{2}{*}{$\begin{array}{l}\text { Source } \\
\text { variation }\end{array}$} & \multirow{2}{*}{$\mathrm{DL}$} & \multicolumn{2}{|c|}{ Carré moyen } \\
\hline & & $\begin{array}{c}\text { Protéines } \\
(\%)\end{array}$ & Lipides $(\%)$ & & & $\begin{array}{l}\text { Protéines } \\
(\%)\end{array}$ & Lipides (\%) \\
\hline Niveau azoté (gluten) & 2 & $0,3 \div 25$ & 5,2461 & Source azotée & 2 & 0,9439 & 7,4399 \\
\hline Sexe ............. & 1 & 0,8580 & 3,9936 & Sexe........ & 1 & 0,9163 & 0,0054 \\
\hline Interactions $\ldots \ldots \ldots$ & 2 & $0,37 \pm 6$ & 2,9097 & Interactions .. & 2 & 0,5813 & 3,3093 \\
\hline Erreur ............ & 18 & 0,3610 & 2,4057 & Erreur ........ & 29 & 0,5294 & 8,2676 \\
\hline
\end{tabular}

Expérience $V$

\begin{tabular}{|c|c|c|c|c|c|c|}
\hline \multirow{3}{*}{$\begin{array}{l}\text { Source de } \\
\text { variation }\end{array}$} & \multicolumn{3}{|c|}{ Lots poisson } & \multicolumn{3}{|c|}{ Lots arachide } \\
\hline & \multirow{2}{*}{ DL } & \multicolumn{2}{|c|}{ Carré moyen } & \multirow{2}{*}{ DI. } & \multicolumn{2}{|c|}{ Carré moyen } \\
\hline & & Protéines $(\%)$ & Lipides (\%) & & P'rotéines $(\%)$ & Lipides (\%) \\
\hline $\begin{array}{l}\text { Niveau azoté : } \\
\text { Terme linéaire ..... } \\
\text { Terme quadratique } \\
\text { Erreur ............ }\end{array}$ & $\begin{array}{r}1 \\
1 \\
17\end{array}$ & $\begin{array}{c}11,3941^{* *} \\
0,0408 \\
0,6100\end{array}$ & $\begin{array}{r}28,1445 \\
1,7693 \\
6,9208\end{array}$ & $\begin{array}{r}1 \\
1 \\
18\end{array}$ & $\begin{array}{l}0,756 \text { \& } \\
0,0059 \\
0,5870\end{array}$ & $\begin{array}{l}1,2230 \\
5,4653 \\
3,0500\end{array}$ \\
\hline
\end{tabular}

Seuil de signification 0,01 .

de la quantité et de la nature des protéines ingérées. D'autre part, 1'exposant du poids étant plus élevé pour les lipides, le pourcentage de lipides augmente relativement plus vite que le pourcentage de protéines lorsque le poids augmente ; c'est le phénomène bien connu de la croissance différentielle.

Il a été procédé à la même série de calculs en considérant les lots des expériences I, II et $\mathrm{P}_{1}$, qui ont duré respectivement $\mathrm{I}_{40}$, I25 et 34 jours. Les relations obtenues (tableau I3, fig. 7) sont sensiblement les mêmes qu'après 8 semaines, ce qui signifie qu'à un poids donné et aux âges considérés, les rats en alimentation séparée présentent la même composition corporelle, quelle que soit la nature de la source azotée. Il y a lieu de noter toutefois des variations importantes dans la teneur en lipides, de sorte qu'il n'est pas possible de déceler de différence d'une expérience à I'autre.

Annales de Biologie animale. - I963. 
(b) essosdos sep!d!
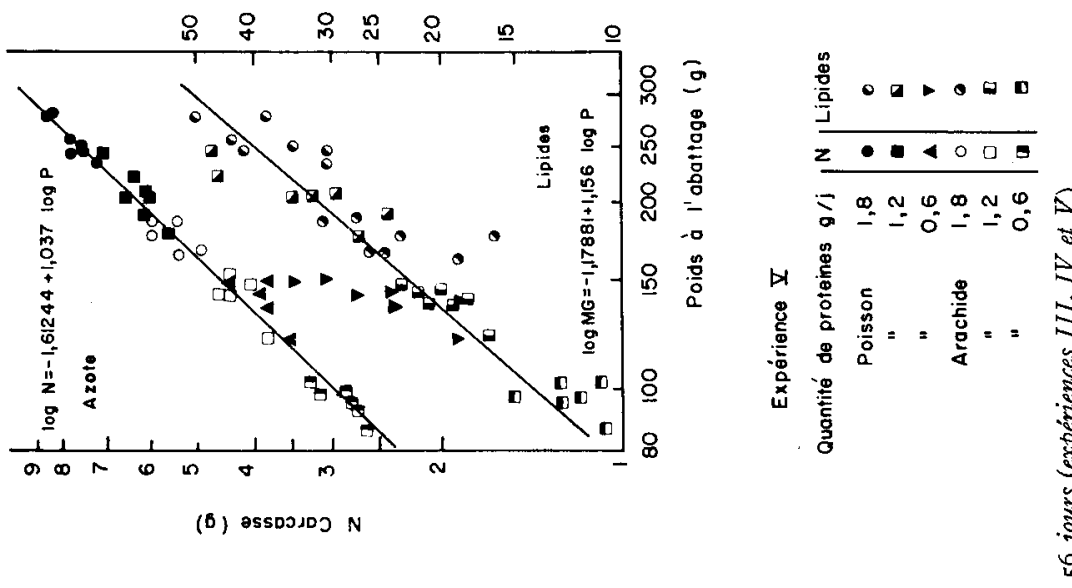

(6) ossovios sop!d!
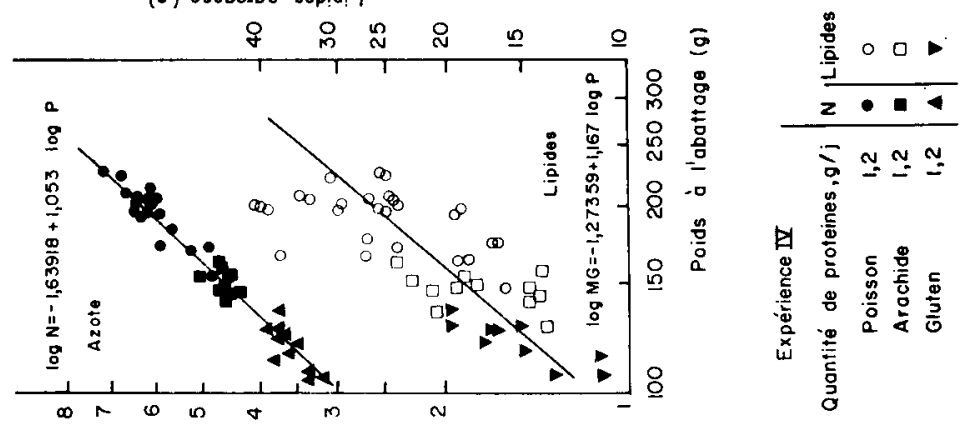

(6) OSSDOADJ N

(5) essoosos sep!d!
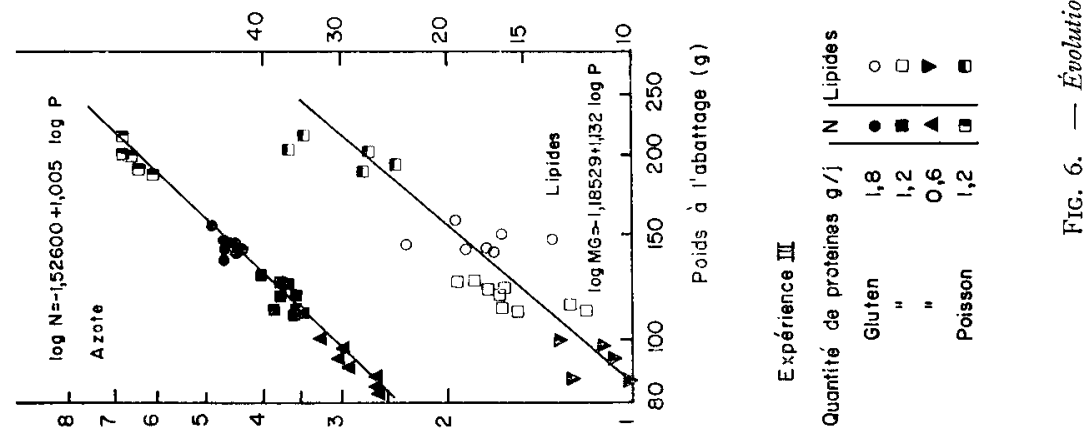

(6) esspong $\mathrm{N}$

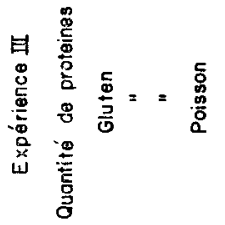


TABI,EAU I3

Equations de régression donnant les quantités d'azote $(N)$, en $g$, et de lipides (MG), en $g$, contenues dans la carcasse en fonction du poids $(P)$ en $g$

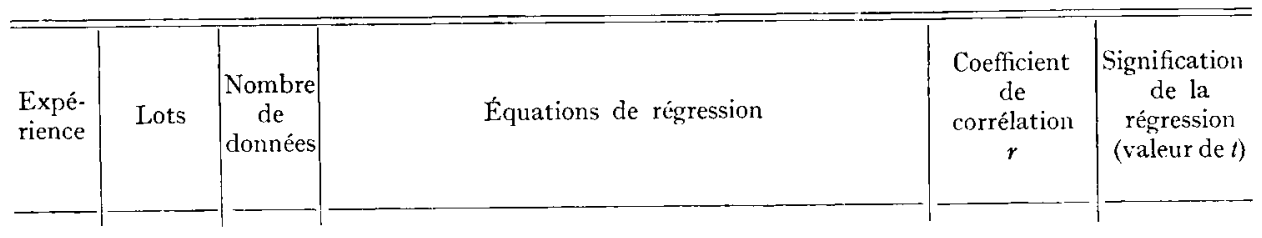

10) Après 56 jours

\begin{tabular}{|c|c|c|c|c|c|c|}
\hline \multirow{2}{*}{ III } & \multirow{2}{*}{ Gluten } & \multirow{2}{*}{24} & $\log \mathrm{N}$ & $\begin{array}{l}=-1,52600+1,005( \pm 0,073)^{(1)} \log \mathrm{P} \\
=\quad 0,336 \mathrm{P}^{1,005}\end{array}$ & 0,987 & $28,63^{* * *}$ \\
\hline & & & $\log \begin{array}{l}\mathrm{MG} \\
\mathrm{MG}\end{array}$ & $\begin{array}{l}=-1,18529+1,132( \pm 0,321) \log \mathrm{P} \\
=0,153 \mathrm{P}^{1,132}\end{array}$ & $0,8 \div 1$ & $7,30 * * *$ \\
\hline \multirow{2}{*}{ IV } & \multirow{2}{*}{$\begin{array}{l}\text { Poisson } \\
\text { Arachide } \\
\text { Gluten }\end{array}$} & \multirow{2}{*}{21} & $\log \frac{N}{N}$ & $\begin{array}{l}=-1,63918+1,053( \pm 0,071) \log \mathrm{P} \\
=0,436 \mathrm{P}^{1,053}\end{array}$ & 0,990 & $30,79 * * *$ \\
\hline & & & $\log \begin{array}{l}\mathrm{MG} \\
\mathrm{MG}\end{array}$ & $\begin{array}{l}=-1,27359+1,167( \pm 0,378) \log \mathrm{P} \\
=\quad 0,188 \mathrm{P}^{\mathbf{1}, \mathbf{1 6 7}}\end{array}$ & 0,811 & $6,05^{* * *}$ \\
\hline \multirow{3}{*}{ V } & Poisson & 20 & $\begin{array}{l}\log \mathrm{N} \\
\log \mathrm{MG}\end{array}$ & $\begin{array}{l}=-0,82834+1,128( \pm 0,086) \log P \\
=-0,4475+0,850( \pm 0,292) \log P\end{array}$ & $\begin{array}{l}0,988 \\
0,822\end{array}$ & $\begin{array}{r}27,58 * * * \\
6,11 * * *\end{array}$ \\
\hline & Arachide & 21 & $\begin{array}{l}\log N \\
\log \mathrm{MG}\end{array}$ & $\begin{array}{l}=-0,59898+1,034( \pm 0,075) \log \mathrm{P} \\
=-1,09230+1,102( \pm 0,261) \log \mathrm{P}\end{array}$ & $\begin{array}{l}0,988 \\
0,896\end{array}$ & $\begin{array}{r}28,80 * * * \\
8,82 * * *\end{array}$ \\
\hline & $\begin{array}{l}\text { Poisson } \\
\text { Arachide }\end{array}$ & 41 & $\begin{array}{ll}\log & N \\
& N \\
\log & M G \\
M G\end{array}$ & $\begin{array}{l}=-1,61244+1,037( \pm 0,050) \log \mathrm{P} \\
=0,10 \mathrm{P}^{1,037} \\
=-1,17881+1,156(\text { 上 } 0,175) \log \mathrm{P} \\
=\quad 0,151 \mathrm{P}^{1,156}\end{array}$ & 0,905 & $\begin{array}{l}41,81^{* * *} \\
13,32^{* * *}\end{array}$ \\
\hline
\end{tabular}

20) Après 140 jours

\begin{tabular}{l|l|l|l|l|l|l}
$\operatorname{I}$ & Poisson & $2 \prime$ & $\mathrm{N}=-1,56288+1,017( \pm 0,127) \log \mathrm{P}$ & 0,962 & $16,56 * * *$ \\
& & $\log \mathrm{MG}=-1,6,1860+1,363( \pm 0,486) \log \mathrm{P}$ & 0,777 & $5,80 * * *$
\end{tabular}

3o) Après 125 jours

II $\quad$ Arachide $\mid 29 \quad$\begin{tabular}{l|l|l|l|r}
$\log \mathrm{N}=-1,69211+1,081( \pm 0,038) \log \mathrm{P}$ & 0,996 & $58,32 * * *$ \\
$\log \mathrm{MG}=-0,95786+1,052( \pm 0,211) \log \mathrm{P}$ & 0,890 & $10,21 * * *$
\end{tabular}

40) Après 3't jours

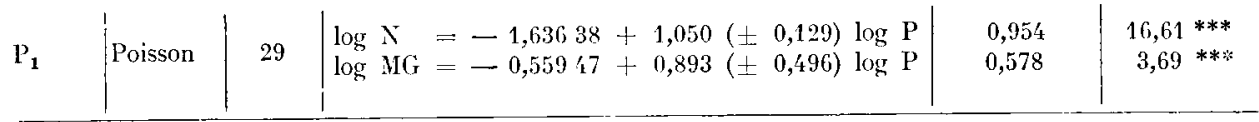

(1) Intervalle de confiance estimé au seuil 0,05 .

$* * *$ Seuil de signification 0,001 . 


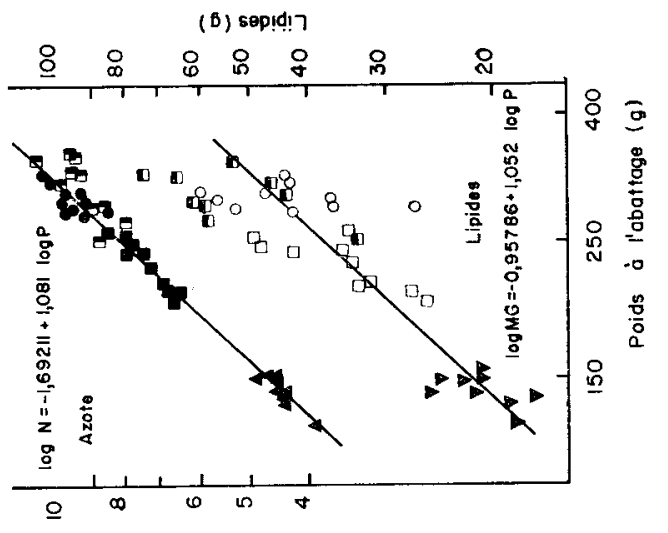

(5) $\mathrm{N}$

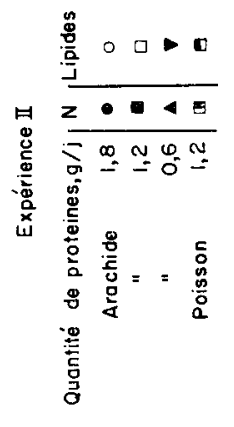

(B) sopid!
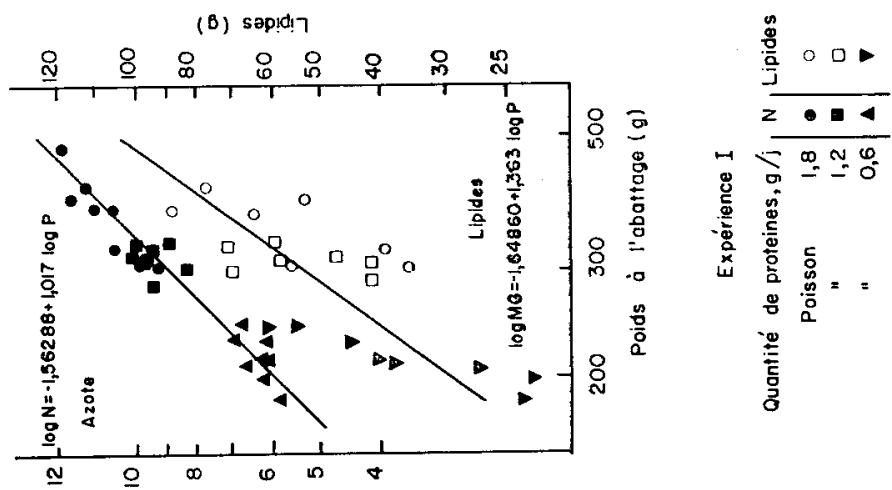

(B) $\mathrm{N}$
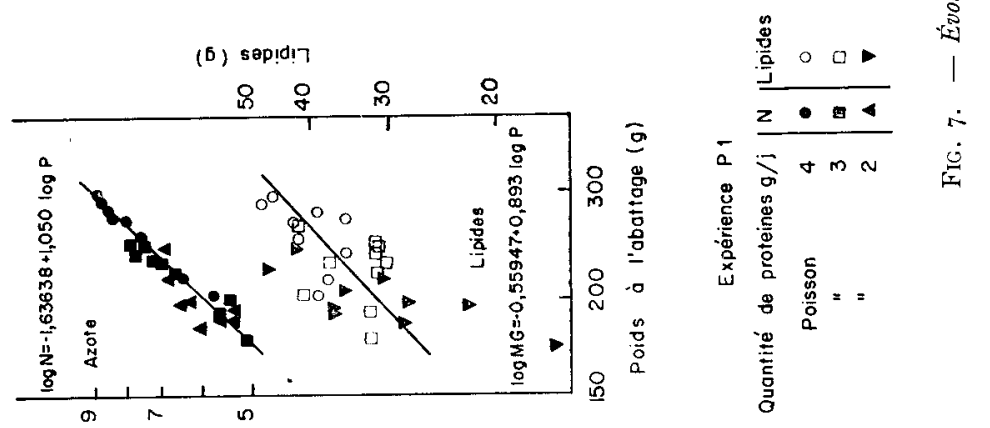

(5) $\mathrm{N}$ 


\section{DISCUSSION}

\section{Observations préliminaires}

I es deux expériences préliminaires ont permis de préciser les modalités d'application de la technique des repas séparés en vue de l'étude de l'ajustement de la consommation d'énergie chez le rat en fonction de l'apport azoté.

\section{a) Niveau d'ingestion azotée}

Il s'agissait tout d'abord de savoir jusqu'à quel niveau on peut faire varier l'apport azoté pour que les animaux soient toujours placés en dessous des conditions de croissance maximum; au-dessus de ce niveau, une partie des protéines serait utilisée à des fins énergétiques et l'étude de l'ajustement n'aurait plus alors de signi fication.

Au cours de la période préexpérimentale, les rats qui recevaient la farine de poisson à volonté et le régime protéiprive $\mathrm{E}$ également à volonté ont constitué des régimes renfermant $28 \mathrm{p}$. roo de protéines. C'est exactement le taux qui a été enregistré dans une autre expérience où les rats recevaient également la farine de poisson et le régime protéiprive à volonté (HENRY et RERAT, I963). Dans cette même étude, il avait été constaté que le rat est incapable d'équilibrer le taux azoté de son régime au niveau de son besoin. Dans ce cas, l'ingestion d'un excès de protéines de poisson entraîne une mauvaise utilisation de ces dernières : le coefficient d'utilisation pratique de l'azote (C. U. P.) est abaissé à 2 I p. Ioo après 8 semaines d'expérience, alors que la valeur maximum observé dans des régimes à 8 p. Ioo de protéines de poisson est de 40 p. Ioo pour des animaux de même âge (RERAT et HENRY, résultats non publiés).

Dans la préexpérience $P_{I}$ les valeurs du C. U. P. pour 2,3 et $4 \mathrm{~g}$ de protéines de poisson par jour, étaient respectivement 33,26 et $25 \mathrm{p}$. roo après une période de 34 jours. Compte tenu du fait que le C. U. P. diminue avec l'âge, les chiffres précédents sont loin d'atteindre la valeur optimum de $40 \mathrm{p}$. Ioo citée plus haut pour une période de 8 semaines. Autrement dit, pour valoriser au mieux la fraction azotée du régime il convenait de réduire la quantité journalière de protéines à moins de $2 \mathrm{~g}$. C'est pourquoi, dans les expériences suivantes, les quantités journalières ont été abaissées à $\mathrm{I}, 8 \mathrm{~g}, \mathrm{I}, 2 \mathrm{~g}$ et $0,6 \mathrm{~g}$, correspondant à 288 , r 92 et $96 \mathrm{mg}$ d'azote.

\section{b) Mode d'administration de la source azotée}

L,e deuxième point de l'étude préliminaire concernait le mode d'apport de la fraction azotée. Fallait-il 1'administrer seule ou en combinaison avec une partie des éléments énergétiques? Depuis les travaux de GEIGER (I948, I950) et MuNRo (I949, r954) on sait en effet que l'ingestion par Je rat, à des temps différents, des éléments azotés et glucidiques, provoque une excrétion d'azote accrue, d'où une rétention plus faible en cet élément. Les résultats obtenus dans l'expérience $\mathrm{P}_{2}$ semblent đémontrer également une action d'épargne de l'énergie sur l'azote, lorsque cet élément n'est pas administré seul, puisque la rétention azotée est améliorée (quoique de façon non significative) pour une même quantité d'énergie ingérée. Dans la suite 
des expériences, il a été décidé d'introduire la source azotée avec une fraction des éléments énergétiques, afin d'éliminer l'influence possible du temps d'ingestion sur la rétention azotée.

\section{c) Infuence du sexe}

Les différences constatées entre animaux mâles et femelles semblent dues principalement à une aptitude de croissance plus élevée chez les mâles que chez les femelles. En effet, l'influence du sexe est d'autant plus marquée que le régime est mieux équilibré (farine de poisson), alors qu'en régime déficient (arachide, gluten) elle est pratiquement négligeable. Dans une précédente publication (HENRY et RERAT, r963), nous avons déjà noté une nette supériorité des mâles sur les femelles dans le cas d'ingestion à volonté d'éléments azotés et énergétiques. Quoi qu'il en soit, à niveau de croissance égal, mâles et femelles répondent de la même façon, tant en ce qui concerne la consommation spontanée d'énergie que la rétention azotée. Par exemple, les femelles du lot " poisson-I,2 " de l'expérience IV et les mâles du lot " arachide- $I, 8$ ) de l'expérience $\mathrm{V}$ ont consommé la même quantité d'énergie, respectivement 50,3 et 50,2 calories par jour, pour réaliser des gains de poids comparables, respectivement $\mathrm{I}, 8 \mathrm{I}$ et $\mathrm{I}, 89 \mathrm{~g} / \mathrm{j}$. La quantité d'azote retenue est également la même dans les deux cas : 59 , I contre $58,9 \mathrm{mg} / \mathrm{j}$. On peut faire la même constatation pour les lots "gluten-I,8 "femelles de 1'expérience III et "arachide-I,2 " mâles de l'expérience IV. Il résulte des observations précédentes que le sexe constitue chez le rat un facteur important de variation, ce qui a conduit à utiliser uniquement des animaux mâles dans les études ultérieures. La sensibijité du test est meilleure avec les mâles, en raison de leur potentialité de croissance plus grande.

\section{Ajustement de la consommation d'énergie sur le poids}

Utilisant également la technique des repas séparés, il a été montré dans une précédente publication (HENRY et RERA'T, I963) que lorsque le rat reçoit à volonté des éléments azotés et énergétiques, il est incapable d'équilibrer le taux azoté de son régime au niveau de son besoin. Par contre, sa consommation d'énergie est en relation étroite avec le poids aux différents stades de la croissance ; elle est proportionnelle au poiđs élevé à une puissance fixe comprise entre 0,32 et 0,35 dans l'intervalle de poids 70-350 g, quelle que soit la nature de la source azotée. Cet ajustement de la consommation d'énergie sur le poids se produit également lorsqu'on limite l'apport azoté en quantité ou en qualité comme c'est le cas dans la série d'expériences considérée ; la consommation d'énergie est cette fois proportionnelle au poids élevé à une puissance voisine de 0,5 dans l'intervalle de poids 6o-I50 g. D'autres auteurs (HARTE et al., I948; HeGstED et HAFFENREFFER, I949) ont trouvé des relations comparables en faisant varier le taux et la nature des protéines du régime. Il convient cependant de remarquer que les travaux cités, portant sur des régimes mixtes, ont été réalisés dans des conditions d'expérimentation différentes des nôtres ; il ne peut s'agir alors à proprement parler d'ajustement de la consommation d'énergie en fonction de 1'apport azoté, puisque les deux facteurs étudiés, énergie et azote, sont associés. Quoi qu'il en soit, les relations obtenues sont comparables dans un cas comme dans l'autre et l'on peut penser que la consommation spontanée d'énergie 
obéit à une loi générale qui est la même quelles que soient la quantité d'azote et la nature de la source azotée.

Lorsqu'on exprime la consommation d'énergie en fonction du poids à la puissance $2 / 3$ et du gain de poids, on obtient dans tous les cas une corrélation très étroite lorsqu'il s'agit du poids. Par contre, le gain de poids contribue pour une faible part dans la variation de la consommation. Pour un niveau de croissance élevé (lots " poisson-I,8 " (poisson-I,2 ) il peut y avoir cependant avantage à tenir compte à la fois du poids et du gain de poids dans l'estimation de la consommation d'énergie. Ceci pourrait expliquer le fait que, si l'on considère uniquement le poids moyen pondéré par quinzaine, l'ingéré calorique, à un poids donné, est légèrement plus élevé avec la farine de poisson qu'avec le tourteau d'arachide ou le gluten de blé (HENRY et RERAT, I962, p. 272). Il est possible que dans le cas de la farine de poisson, le mode de représentation du poids vif ne tienne pas assez compte de la vitesse de croissance; les animaux, ayant alors une croissance plus rapide, ingéreraient, plus d'énergie pour un poids donné. Notons également que, pour le calcul des calories brutes ingérées, il a fallu utiliser certains coefficients dont la portée n'est peut être pas universelle ; ceci permettrait d'expliquer également les écarts entre les ordonnées à l'origine des droites de régression, quoique ces derniers soient très loin d'atteinđre le seuil de signification.

\section{Ajustement de la consommation d'énergie sur la rétention azotée}

Dans une note précédente en collaboration avec ABRAHAM, CALET et JACQUOT (I96r), nous avions montré que la consommation spontanée d'énergie, chez le rat comme chez le poulet, est étroitement contingente de l'apport azoté, quantitatif ou qualitatif. Effectivement, les résultats obtenus au cours de la présente étude confirment l'existence d'une relation linéaire entre l'ingéré calorique et la quantité d'azote retenue dans les tissus, indépendamment de la valeur biologique des protéines. Autrement dit, c'est la fraction des acides aminés indispensables pour la croissance et l'entretien qui détermine le niveau de consommation énergétique.

MunRo et Narsmirh (I953) ont montré également qu'à un niveau d'ingestion d'azote donné il existe une relation linéaire entre la quantité d'énergie ingérée par unité de surface corporelle et l'azote retenu; ils en concluent que la fraction des protéines utilisée à des fins énergétiques varie en raison inverse de la quantité d'énergie provenant des autres sources alimentaires (glucides, lipides) et que, pour une quantité donnée de protéines, l'énergie disponible constitue le facteur limitant de la synthèse protéique.

Bien entendu, la relation obtenue entre l'ingéré calorique et la rétention azotée, pour des rétentions moyennes journalières comprises entre ro et roo mg d'azote, n'est valable que dans nos conditions expérimentales, c'est-à-dire pour des animaux dont le besoin d'entretien est comparable d'une expérience à l'autre (durée de l'expérience identique, poids moyen des lots peu différent) et dont le besoin azoté pour une croissance maximum n'est pas couvert. Ainsi, la valeur plus faible obtenue pour la pente de la droite de régression dans les lots poisson $(0,275$ au lieu de 0,325$)$ semble due au fait que les animaux sont plus lourds en fin de croissance par rapport aux animaux des autres lots. Il est possible que la relation précédente soit encore maintenue pour des niveaux de croissance élevés si l'on rapporte la consommation d'éner- 
gie à l'unité de surface corporelle, comme le propose Narsmitr, ce qui signifie que l'évolution de 1'ingéré calorique en fonction de la rétention azotée présente alors une allure exponentielle.

L'existence d'une relation constante entre la consommation spontanée d'énergie et la rétention azotée s'explique encore par le fait que le coefficient d'utilisation pratique de l'azote (C. U. P.) est peu modifié lorsqu'on fait varier le niveau azoté ; étant donné que l'ingéré calorique croît linéairement avec ce dernier, il y a tout lieu de penser qu'il en est de même en fonction de l'azote retenu.

D'autre part, il convient de remarquer que 1'évolution des critères d'efficacité azotée (C. E. P., C. U. P.) en fonction du niveau azoté est la même en alimentation séparée et en régime mixte, utilisant les mêmes protéines à des taux variables. Ainsi, d'après nos propres observations et celles d'autres auteurs (BARNEs et BosSHARDT, I946), la valeur maximum du C. E. P. (ou du C. U. P.) est d'autant plus élevée, et le niveau azoté correspondant d'autant plus faible, que la source azotée est de meilleure qualité (dans l'ordre : farine de poisson, tourteau d'arachide, gluten de blé). Cependant, les variations du C. E. P. (ou du C. U. P.) en fonction du niveau azoté semblent nettement plus faibles en alimentation séparée qu'en régime mixte, pour des niveaux d'ingestion comparables. Par exemple, dans le cas de la farine de poisson, les valeurs du C. U. P. après 8 semaines d'expérience, pour des régimes à 4,8 et I2 p. Ioo de protéines (correspondant à des ingestions journalières de $0,60,-I, 38$ et $2, I 2 \mathrm{~g}$ de protéines) sont respectivement $2 \mathrm{I}, 6,-40,4$ et 33,3 p. IOo (RERAT et HENRY, résultats non publiés) ; par contre, les valeurs obtenues dans la présente étude pour $0,6-\mathrm{I}, 2$ et $\mathrm{I}, 8 \mathrm{~g} / \mathrm{j}$ de protéines de poisson sont comprises dans des marges beaucoup plus étroites, soit respectivement $35,5,-39,2$ et $37,6 \mathrm{p}$. Ioo (tableau 7 ). I1 y a lieu cependant de noter que ces résultats concernent des expériences qui ont été réalisées à des époques différentes et dans des conditions différentes ; d'une part l'ingestion journalière de protéines en régime mixte n'a pas été constamment la même $(0,46 \mathrm{~g}$ au début de la croissance et $0,64 \mathrm{~g}$ en fin de croissance dans le cas du régime à $4 \mathrm{p}$. Ioo de protéines) ; d'autre part, le poids initial a été également différent : ' $00 \mathrm{~g}$ en régime mixte au lieu de $70 \mathrm{~g}$ en alimentation séparée. Compte tenu de ces réserves, et puisque le C. U. P. présente peu de variations en fonction du niveau azoté, on peut penser que la libre consommation énergétique permet à l'animal d'utiliser les protéines plus en fonction de leur composition que du niveau azoté imposé ; au contraire, en régime mixte, la variabilité de l'efficacité azotée en fonction du niveau d'ingestion est plus grande. Il pourrait s'agir là d'un test d'évaluation de la valeur des protéines, plus précis que la méthode habituellement préconisée (régime à Io p. Ioo de Mac Cor,Lum, I938). Il est d'ailleurs connu que l'utilisation maximum de l'azote est obtenue à partir d'un certain niveau de consommation énergétique (BOSSHARDT et al., I946; ForBes et YoHe, I955). Lorsque le rat dispose d'une quantité d'azote limitée et de l'énergie à volonté, il paraît précisément en mesure d'utiliser l'azote avec le maximum d'efficacité, même dans des limites d'ingestion azotée relativement importantes.

\section{Composition corporelle}

L'étude de 1'évolution des quantités d'azote et de lipides dans la carcasse a montré qu'à un poids donné les rats recevant l'énergie à volonté et l'azote en quantité limitée présentent la même composition corporelle quelle que soit la nature de la 
source azotée. Autrement dit, pour un niveau de croissance donné, la quantité de lipides déposés par rapport à l'azote retenu est la même pour différentes sources azotées. Or, il est connu que dans les conditions habituelles d'alimentation, c'est-àdire en régime complet, il en va différemment. Ainsi ALIIISON (I957) administrant à des chiots soit des protéines d'œuf soit des protéines de gluten de façon qu'ils réalisent le même gain de poids, a constaté que les animaux nourris au gluten présentent une rétention azotée moindre et sont plus gras que ceux revevant des protéines d'œuf; dans le cas du gluten, protéine de mauvaise qualité, l'ingestion d'un excès d'énergie par rapport aux protéines a entraîné un dépôt accru de graisse. Au contraire, en alimentation séparée, la consommation d'énergie pour une même quantité de gluten aurait été moindre et, par conséquent, le dépôt de graisse aurait été également plus taible. Nous avons d'ailleurs observé que lorsque les rats reçoivent, en régime complet, les mêmes protéines qu'en alimentation séparée, à des niveaux comparables d'ingestion; ils ont tendance à être plus gras (RERAT et HENRY, résultats non publiés). Cependant, les expériences n'ayant pas été effectuées en même temps, cette observation néces site une vérification.

\section{CONCLUSION}

En définitive, lorsqu'on administre au rat, simultanément dans deux mangeoires séparées, des substances azotées en quantité limitée (inférieure au besoin pour une croissance maximum) et des éléments énergétiques à volonté, la consommation spontanée d'énergie varie avec la quantité et la nature des protéines ingérées; elle est d'autant plus importante que le niveau azoté est plus élevé et que la protéine utilisée est de meilleure qualité. Cet accroissement de la consommation de calories s'accompagne d'une amélioration de la croissance et de l'efficacité alimentaire (indice de consommation, rétentions azotée et énergétique). En valeur relative, la quantité de calories ingérées par g d'azote diminue lorsque la quantité d'azote augmente ou lorsque l'on utilise des protéines d'efficacité protidique plus faible.

Quels que soient le niveau azoté et la nature de la source azotée, l'ingestion d'énergie au cours de la croissance est proportionnelle au poids élevé à une puissance fixe (voisine de 0,5 dans l'intervalle de poids $60-150 \mathrm{~g}$ ). D'autre part, il existe une relation linéaire constante entre la consommation d'énergie et la quantité d'azote retenue dans les tissus, tandis que la composition corporelle, à un poids donné, est la même quelle que soit la nature de la source azotée. Ceci démontre l'existence d'un phénomène d'ajustement de la consommation d'énergie en fonction de l'apport azoté, quantitatif ou qualitatif. Plus précisément, c'est 1a fraction des protéines administrées, utilisable pour la croissance, qui détermine le niveau de consommation énergétique.

Reçu pour publication en juin 1963

\section{SUMMARY}

THE VOLUNTARY ENERGY CONSUMPTION OF THE GROWING RAT IN RELATION TO THE QUANTITY AND QUALITY OF PROTEIN IN THE DIET

The voluntary energy intake of the growing rat has been studied by feeding separately during 8 weeks, in two separate troughs, a fixed quantity of a protein diet and a protein free diet ad libitum. Three protein sources of a known origin (herring meal, extracted peanut oil meal, wheat gluten 
meal) were used at three levels each ( $0.6, \mathbf{1} .2$ and $\mathrm{I} .8 \mathrm{~g}$ of protein per day) in a series of experiments with lots of 8 to 12 Wistar albino rats.

When the dietary protein does not allow maximum growth, the voluntary energy intake increases with the protein level; at a given protein level, the higher the protein quality, the higher the energy consumption. The calorie/protein ratio decreases when the protein level is raised or when the quality of protein is lowered. In any case, increasing energy consumption improves growth rate, feed efficiency, nitrogen and energy retention.

Whatever the quantity and/or the quality of the protein be fed, there is a linear relationship between the daily calorie intake in a given body weight interval (60 to $150 \mathrm{~g}$ ) and the body weight raised to a fixed power (around 0.5 ). A constant linear relationship also occurs between the energy consumption and the quantity of nitrogen retained in the body, while the body composition is the same at a given body weight for the three protein sources used.

These results support the hypothesis of a regulation of the energy intake according to the growth impulse allowed by the dietary protein, which is in this case the limiting factor.

\section{RÉFÉRENCES BIBLIOGRAPHIQUES}

Abraham J., Calet C., Rerat A., JaCquot R., ig6r. Solidarité des besoins énergétique et protéique de croissance : l'ajustement spontané des calories et des protides. C. R. Acad. Sci. Paris, 253, 2768-2770.

Allison, 1957. Calories and protein nutrition. Ann. N. Y. Acad. Sci., 69, roog-ror8.

Atwater W.O., Bryant A. P., 1903. The chemical composition of american food materials. $U . S$. Dept. Agr. Bull., 28.

Barnes R. H, Bossiart D. K., I946. The evaluation of protein quality in the normal animal. Ann. N. Y. Acad. Sci., 47, 273-294.

Bosshardt D. K., Winifred P., O'Doherty K., Barnes R. H., ig46. The influence of caloric intake on the growth utilization of dietary protein. J. Nutr., 32, 64I-65I.

Brody S., 1945. Bioenergetics and growth, ro23 pp. Reinhold Pub. Corp., New York.

Byerly T. C., I94I. Feed and other costs of producing market eggs. Maryland Agric. Exp. Sta. Bull. 346, т-29.

Calet C., Jouandet C., Baratou J., 196r. Variation de la consommation spontanée d'énergie du poussin en fonction de la nature des matieres azotées du régime. Ann. Biol. anim. Bioch. Biophys., 1, 1-9.

Coop I. E., I962. The energy requirements of sheep for maintenance and gain. J. Agric. Sci., 58, 179 -199.

Forbes R. M., RaO T., I959. The effect of age on the net requirement for Nitrogen, Lysine and Tryptophane by the well-fed rat. Arch. Biochem. Biophys., 82, 348-354.

Forbes R. M., YoHE M., I955. Effect of energy intake on the biological value of protein fed rats. $J$. Nutr., 55, 499-506.

Garrets W. N., Meyer J. H., Lofgreen G. P., I959. The comparative energy requirements of sheep and cattle for maintenance and gain. J. Anim. Sci., 18, 528-547.

GEIGer E., I948. The role of the time factor in feeding supplementary proteins. J. Nutr., 36, 8I $3-8$ I9.

Geiger E., Bancroft R. W., Hagerty E. B., i950. The-nitrogen sparing effect of dietary carbohydrate in its relation to the time factor. Experiments with repletion of protein depleted adult rats. J. Nutr., 42, $577-585$.

Harte R. A., Travers J. J., SARICh P., r948. Voluntary caloric intake of the growing rat. J. Nuir., 36, $677-679$.

Hegsted D. M., Haffenreffer V. R., 1949. Caloric intake in relation to the quantity and quality of protein in the diet. Amer. J. Physiol, 15\%, 141-148.

Henry Y., Rerat A., ig6z. Influence de la qualité et de la quantité des matières azotées ingérées sur la consommation spontanée d'énergie chez le rat en croissance. Ann. Biol. anim. Bioch. Biophys., 2, 267-276.

Henry Y., Rerat A., I963. Étude de l'ingestion spontanée d'éléments énergétiques et de protéines chez le rat en croissance par la méthode du libre choix. Ann. Biol. anim. Bioch. Biophys., 3, 103-1 I7.

Mc Collum E. V., Crent Keiler E., Day H. G., I938. The nerver knowledge of nutrition, $5^{\mathrm{e}}$ edit., New York.

MunRo II. N., r949. The relationship of carbohydrate of metabolism to protein metabolism. III - Further observations on time of carbohydrate ingestion as a factor in protein utilization by the adult rat. $J$. Nutr., 39, 375-391.

Munko H. N., 1951. Carbohydrate and fat as factors in protein utilization and metabolism. Physiol. Rev., 31, 449-488.

Munro H. N., Naismiti D. J., 1953. The influence of energy intake on protein metabolism. Biochem. $J$, 54, I9I-197.

Munro H. N., Wikramanayake, I954- Absence of a time factor in the relationship between level of energy intake and protein metabolism. J. Nutr., 52, 99-r44.

Rerat A., Henry Y., ig63. (Données non publices.)

Rerat A., Henry Y., Jaçuot R., ig63. Relation entre le consommation spontanée d'énergie et la rétention azotée chez le rat en croissance. C. R. Acad. Sci. Paris, 256, 787-789.

SNEDECOR G. W., I956. Statistical methods applied to experiments in agriculture and biology. 5e ed., $534 \mathrm{pp.}$ The Iowa State University Press, Ames, Iowa. 